\title{
MAIN CHAIN POLYAMIDE ROTAXANES FROM ALIPHATIC CROWN ETHERS
}

\author{
Herve' Lefebvre, ${ }^{a}$ Mukesh Bheda, ${ }^{\mathrm{b}}$ Harry W. Gibson * \\ Department of Chemistry and Macromolecules \& Interfaces Institute \\ Virginia Tech, Blacksburg, Virginia 24061
}

\begin{abstract}
Main chain polyaramides were prepared by the Highashi protocol from oxydianiline (ODA) and isophthalic acid (ISOPA) in the presence of 30-crown-10 and "60-crown-20". Relatively small amounts of the smaller macrocycle were incorporated ( $<2$ mass \%), but the larger one resulted in $\sim 17$ mass \% incorporation. These polymers display a previously observed irreversible high temperature exothermic transition that is attributed to a solid-state reorganization to intermolecularly hydrogen bonded amide pairs. An analogous set of polymers was prepared from bis $(p-$ aminophenyl)fluorene (FLUODA) and ISOPA, with similar results, except that the exothermic transition was not observed. A main chain polypseudorotaxane was also prepared from Nylon-6,6 by condensation of adipoyl chloride and hexamethylene diamine in the presence of 30-crown-10; again only a small amount ( $\sim 5$ mass $\%)$ of the macrocycle was threaded onto the backbone.
\end{abstract}

a Present address: Laboratoire de Chimie des Polymères, Université Pierre et Marie Curie, 4 Place Jussieu, 75005 Paris, France. herve.lefebvre@upmc.fr

b_Product Regulation Group, BP, Naperville , Illinois. mukesh.bheda@bp.com

* e-mail: hwgibson@vt.edu 


\section{INTRODUCTION}

Pseudorotaxanes in recent years have attained a special status in supramolecular chemistry because they are intermediates in the formation of rotaxanes and catenanes ${ }^{1}$ (Scheme 1) and their polymeric analogs. ${ }^{2}$ In prior efforts we have prepared both main chain and side chain polypseudorotaxanes and rotaxanes from a variety of macromolecules; of particular interest in the present context, we have examined polyester rotaxanes ${ }^{3}$ and polyurethanes ${ }^{4}$ synthesized in the presence of aliphatic crown ethers and also from bis( $m$-phenylene)-based crown ether diols ${ }^{3 g, 3 h, 3 i, 4 e}$ and polyamides using bis( $m$-phenylene)-based crown ether diacids. ${ }^{5}$ We have also prepared and studied polystyrene- ${ }^{6}$ and poly(meth)acrylate-based polyrotaxanes ${ }^{7}$ prepared by polymerizations in crown ether solvents.

Aliphatic and aromatic polyamides are important classes of polymers because of their useful properties, e. g., high thermal stability, hydrolytic stability, solvent resistance and good mechanical properties. $^{8}$ Polyamides can be obtained by interfacial, solution or melt polycondensation and by ring opening polymerization. In the synthesis of polyaramides, the preferred method is usually low temperature polycondensation using diacid chlorides and

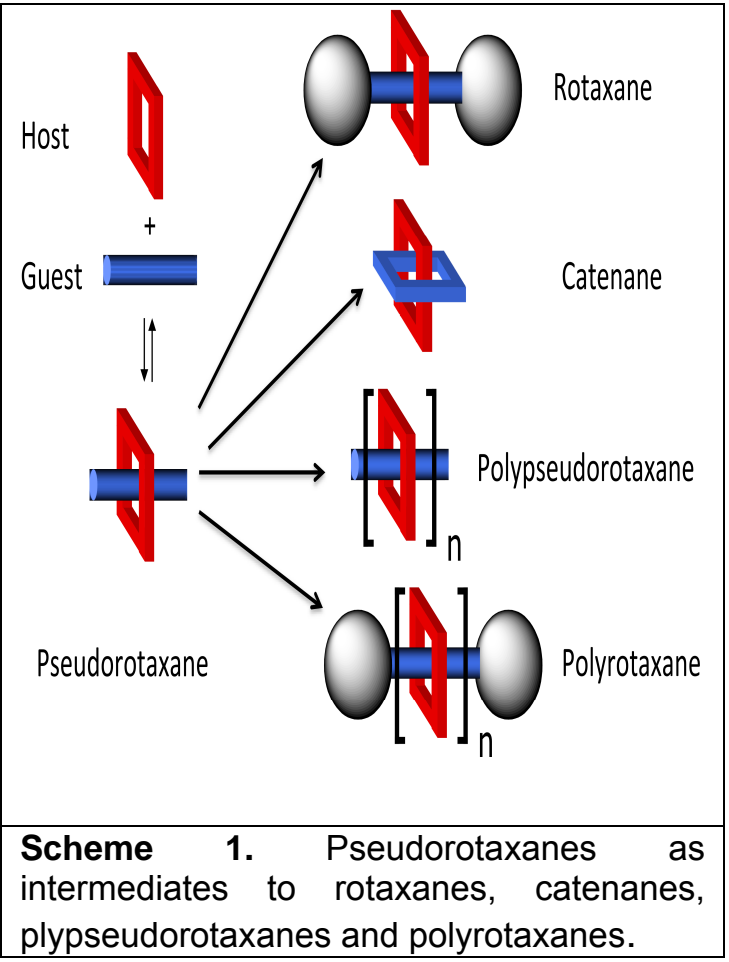
diamines. Alternatively, Higashi et al. ${ }^{9}$ have reported the syntheses of a great variety of aramides by direct polycondensation of aromatic diacids and diamines in solution using phosphites in the presence of metals salts. Depending on the monomers and other 
reaction parameters, high molecular weight aromatic polyamides can be obtained. Semi-aromatic polyamides can also be synthesized in this way. ${ }^{9 j}$

However, these polymers are usually difficult to process because of their low solubilities, high melting temperatures and viscosities. Thus, the synthesis of polyamide pseudorotaxanes or rotaxanes seemed to be an attractive way to improve the solubility and processability by incorporating polar, highly soluble crown ethers on the main chain (threading), while retaining other useful properties. Hydrogen bonding of crown ethers with diamines and dicarboxylic acids was perceived as a driving force to form the requisite pseudorotaxane intermediates (Scheme 1).

\section{RESULTS AND DISCUSSION}

\section{A. Isophthalic Acid-Oxydianiline-Based Polymers}

\section{Model System and 30-Crown-10-Based Polyrotaxanes}

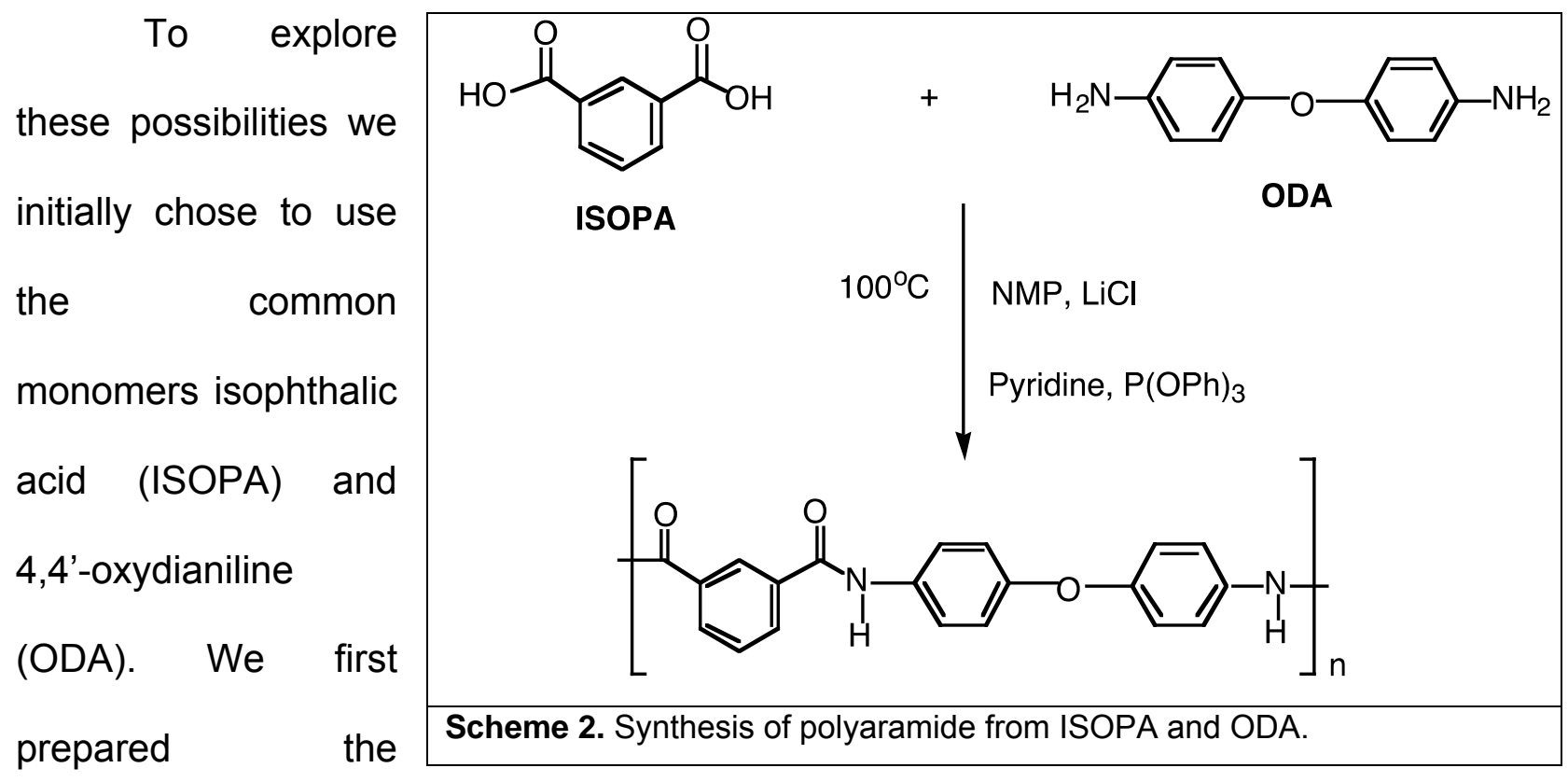

polyamide from ODA and ISOPA using the Higashi protocol (Scheme 2). Then, the same reaction was done in the presence of 30-crown-10 (30C10) (Scheme 3). As can 
be seen, these polymers had about the same molecular weights (Table 1, HL31, HL33). Precise stoichiometry between the two monomers is an important factor in polycondensation reactions. However, because the supply of crown ether was limited all reactions were done in small scale and thus imprecise stoichiometry likely explains the relatively low molecular weights.

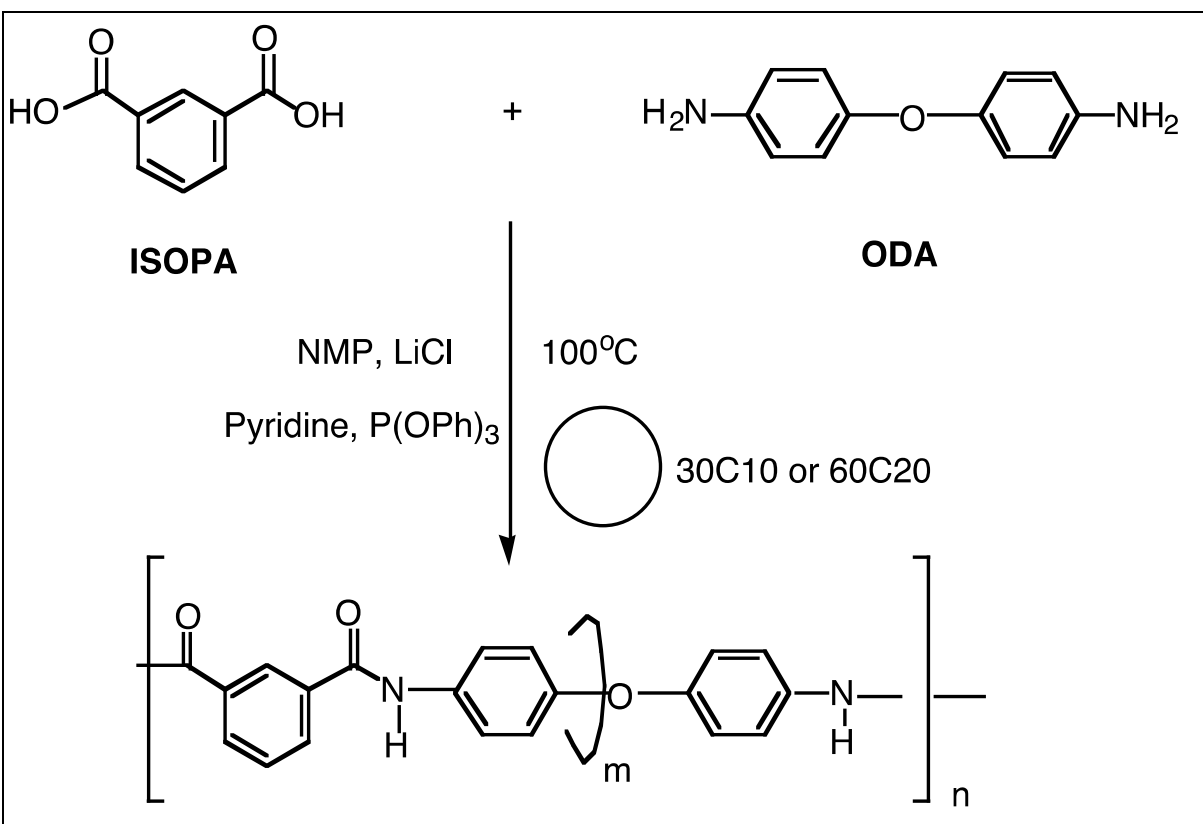

Scheme 3. Synthesis of polyamide-rotaxa-crown ethers from ISOPA and ODA.

In addition, the molecular weights of the polyrotaxanes are lower than their model counterparts. This could be explained by the excess of crown ether employed, which resulted in lower monomer concentrations. Moreover, Higashi et al. ${ }^{9 b}$ showed that poly(ethylene oxide) (PEO) can greatly influence the molecular weight of the final polyamide. When $0.5 \%$ wt of PEO $\left(M_{n} 20-500 \mathrm{kDa}\right)$ was added to the reaction mixture, higher molecular weights were obtained. However, when the amount of PEO was increased or the $M_{n}$ was decreased (e. g., to $400 \mathrm{Da}$ ), lower molecular weights were found than in the absence of PEO. ${ }^{9 b}$ Since crown ethers derive from the same repeat unit, it is reasonable to think that they may have the same influence as the low molecular weight PEO.

An important factor with the synthesis of polyrotaxanes is the purification step. The polymers were dissolved in NMP and precipitated into methanol several times in order to remove any free (unthreaded) macrocycle. The polyamide rotaxanes were 
Table 1. Polyamide (Pseudo)rotaxanes.

\begin{tabular}{|c|c|c|c|c|c|c|c|}
\hline SAMPLE & $\begin{array}{c}\text { DIAMINE } \\
\text { (conc., M) }^{c}\end{array}$ & CROWN & $\begin{array}{l}\text { CROWN I } \\
\text { DIAMINE }\end{array}$ & $\begin{array}{c}M_{n}{ }^{a} \\
(k D a)\end{array}$ & $\mathrm{PDI}^{\mathrm{a}}$ & $m / n^{b}$ & $\begin{array}{c}\text { Mass \% } \\
\text { Crown }\end{array}$ \\
\hline HL33 & ODA (0.39) & $\begin{array}{ll}--- \\
\end{array}$ & 0 & 11.2 & 1.53 & 0 & 0 \\
\hline HL31 & ODA (0.19) & $30 \mathrm{C} 10$ & 4.0 & 9.80 & 1.46 & 2: 0.00392 & $2: 0.52$ \\
\hline HL51 & ODA (0.26) & $30 \mathrm{C} 10$ & 4.2 & $\begin{array}{l}1: 4.80 \\
2: 5.69\end{array}$ & $\begin{array}{l}1: 1.41 \\
2: 1.27\end{array}$ & $\begin{array}{c}1: \text { ND } \\
\text { 2: } 0.016^{\S} \\
\text { 3: } 0.014\end{array}$ & $\begin{array}{c}1: \text { ND } \\
2: 2.1 \\
3: 1.8\end{array}$ \\
\hline HL121 & ODA (0.16) & $30 \mathrm{C} 10$ & 4.0 & 7.97 & 1.38 & $\begin{array}{l}1: 0.0023^{\S} \\
2: 0.0024\end{array}$ & $\begin{array}{l}1: 0.30^{\S} \\
2: 0.32\end{array}$ \\
\hline HL139 & ODA (0.51) & “60C20” & 1.0 & 8.47 & 1.64 & $\begin{array}{c}\text { 1: } 0.0920 \\
\text { 2: } 0.0693 \\
\text { 2: } 0.0781^{\text {H }}\end{array}$ & $\begin{array}{c}\text { 1: } 19.6 \\
\text { 2: } 15.6 \\
\text { 3: } 17.2^{\mathscr{H}}\end{array}$ \\
\hline HL58 & FLUODA (0.25) & --- & 0 & 8.47 & 1.40 & 0 & 0 \\
\hline HL88 & FLUODA (0.27) & $30 \mathrm{C} 10$ & 4.0 & 10.3 & 1.48 & $\begin{array}{c}1: 0.00293 \\
3: 0.0034\end{array}$ & $\begin{array}{l}1: 0.27 \\
3: 0.32\end{array}$ \\
\hline HL137 & FLUODA (0.25) & “60C20” & 1.0 & 9.14 & 2.10 & $\begin{array}{c}1: 0.164 \\
2: 0.141 \\
2: 0.168^{\not b}\end{array}$ & $\begin{array}{c}1: 23.2 \\
2: 20.6 \\
2: 23.68\end{array}$ \\
\hline HL115 & FLUODA (0.16) & $30 C 10$ & 4.0 & 6.93 & 1.54 & $\begin{array}{c}1: 0.015^{\S} \\
2: 0.0070\end{array}$ & $\begin{array}{l}1: 1.37^{\S} \\
0.64\end{array}$ \\
\hline HL99 & $\begin{array}{c}\text { ODA/FLUODA } \\
80: 20(0.26)\end{array}$ & $30 C 10$ & 4.1 & 8.44 & 1.32 & $1: 0.0016^{\S}$ & $1: 0.20$ \\
\hline HL101 & $\begin{array}{c}\text { ODA/FLUODA } \\
80: 20(0.50)\end{array}$ & ---- & 0 & 8.82 & 1.45 & ---- & ---- \\
\hline $\begin{array}{c}\text { MB-II- } \\
277\end{array}$ & $\begin{array}{c}\text { Nylon-6,6 } \\
(0.17)\end{array}$ & $30 \mathrm{C} 10$ & 1.28 & ---- & ---- & $\begin{array}{l}\text { 1: } 0.042^{*} \\
2: 0.024^{*}\end{array}$ & $\begin{array}{l}1: 8.3^{*} \\
2: 4.8^{*}\end{array}$ \\
\hline
\end{tabular}

${ }^{a}$ Determined by GPC (20 mM P $\mathrm{O}_{5}$ in NMP) with viscosimetric detector and universal calibration. ${ }^{b}$ Precipitation from NMP into methanol, unless otherwise noted; analysis by ${ }^{1} \mathrm{H}$ NMR in DMSO- $d_{6}$, unless otherwise noted; error in $\mathrm{m} / \mathrm{n} \pm 10 \%$ relative. ${ }^{c}$ Concentrations estimated by assuming liquids had density of $1.0 \mathrm{~g} / \mathrm{mL}$ and solids did not contribute. ND: not determined. - Only threaded 30C10 peak observed. ${ }^{\S}$ By deconvolution of peaks for threaded and unthreaded crown ether (see SI, Figure S4); error in $\mathrm{m} / \mathrm{n} \pm 15 \%$ relative. H Precipitation from DMSO into methanol. * Polymer washed extensively with methanol; ${ }^{1} \mathrm{H}$ NMR in $\mathrm{CF}_{3} \mathrm{COOD}$; error in $\mathrm{m} / \mathrm{n} \pm 10 \%$ relative. 
studied by GPC in order to detect the presence of free macrocycle (Figure 1). As can be seen, 30C10 elutes with the solvent, and from these results we conclude that there is no free $30 \mathrm{C} 10$ in the polyrotaxane after the second precipitations. For later discussion it should be noted that the larger macrocycle ("60C20") behaved similarly in GPC elution. These results are consistent with earlier findings; aliphatic crown ethers elute near the solvent, well removed from their polyrotaxanes. ${ }^{3 a, 3 d, 3 f, 4 a, 4 b, 6 a, 6 b, 7 c}$

To corroborate this conclusion the polymers were studied by ${ }^{1} \mathrm{H} \quad \mathrm{NMR}$ spectroscopy. The ${ }^{1} \mathrm{H}$ NMR spectrum of the model polymer from reaction between ODA and ISOPA (HL33) contains the two expected doublets for $\mathrm{H}_{\mathrm{e}}$ and $\mathrm{H}_{\mathrm{f}}$ at 7.79 and $7.03 \mathrm{ppm}$, respectively. The three protons $H_{a}, H_{b}$ and $H_{c}$ from the isophthalic moiety give three resonances at $8.51,8.13$ and $7.67 \mathrm{ppm}$, respectively, and a peak at 10.44

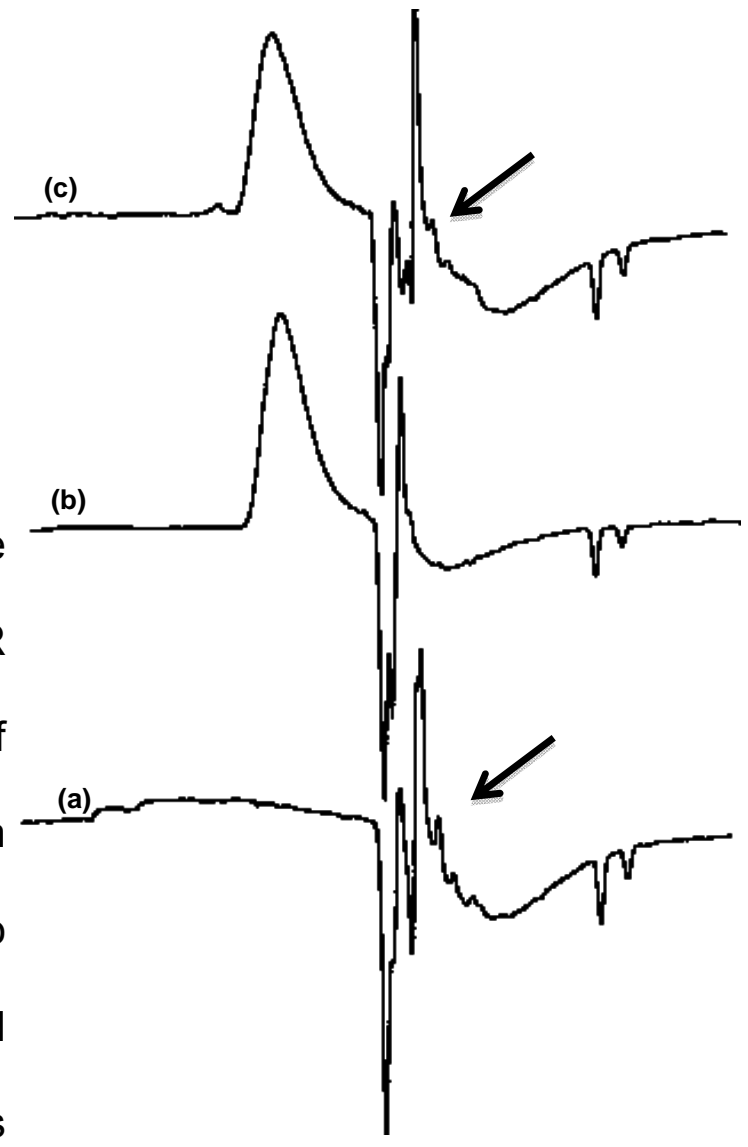

Figure 1. Stacked GPC traces (NMP, RI detector) of (a) 30C10, (b) IPA/ODA model polymer HL-33, (c) mixture of $30 \mathrm{C} 10$ and HL-33 (50/50, w/w).

ppm corresponds to the $\mathrm{CO}-\mathrm{NH}$ protons.

The polyrotaxane counterpart HL31 gave the same spectrum with nearly the same chemical shifts with the addition of resonances from the 30C10 (Figure 2). After the first precipitation, a strong signal from the free macrocycle can be seen at $3.49 \mathrm{ppm}$; however, a shoulder located slightly upfield at $3.48 \mathrm{ppm}$ is assigned to the threaded 
macrocycle, as we previously observed with this rather small crown ether when it is threaded onto polymers containing aromatic backbone units. ${ }^{3 c, 3 e, 3 f, 4 d}$ The shift for the threaded macrocycle is due to the shielding effect of the intimately enshrouded aromatic rings. After two or three precipitations, all free macrocycle was removed, as shown for HL-51 in Figure 3.

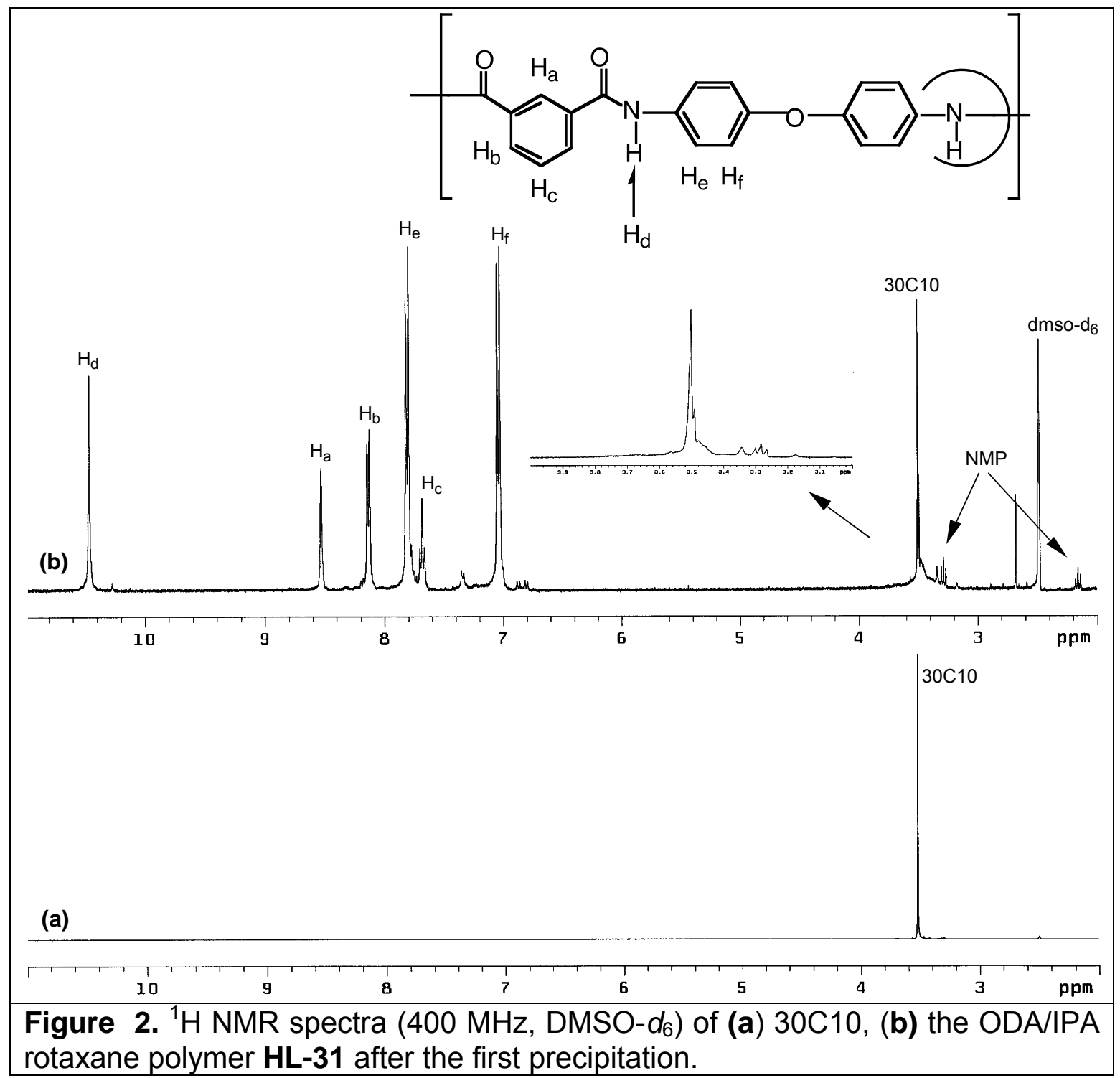




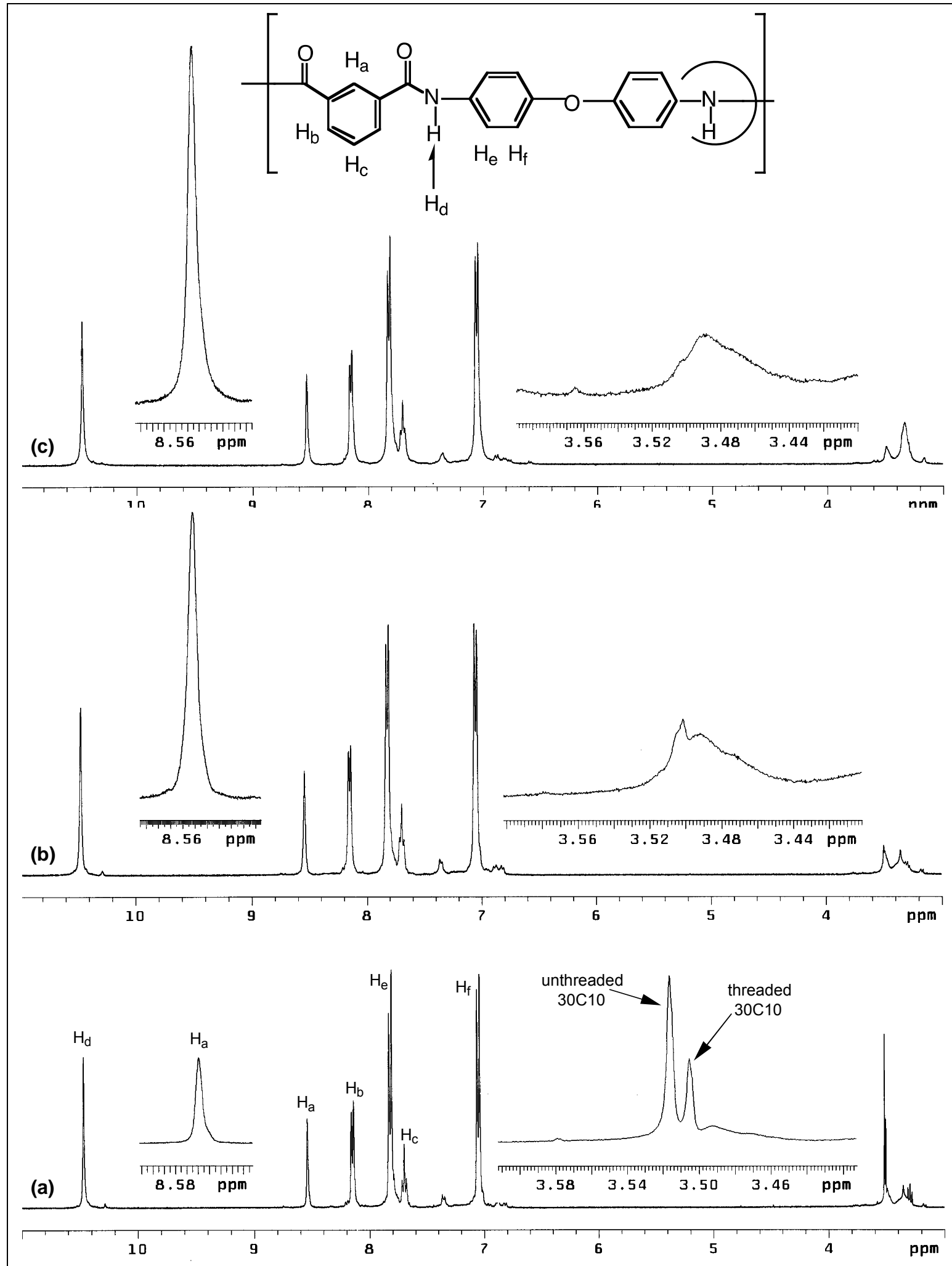

Figure 3. ${ }^{1} \mathrm{H}$ NMR spectra $\left(400 \mathrm{MHz}\right.$, DMSO- $\left.d_{6}\right)$ of the ODA/IPA/30C10 rotaxane polymer HL-51 (a) after the first precipitation, (b) after the second precipitation, (c) after the third precipitation. 
The polymer compositions were determined after the second or third precipitation, affording the $\mathrm{m} / \mathrm{n}$ values, the molar ratios of macrocycle to repeat units of the polymer backbone (Table 1), using the integrals of the threaded crown ether signal and $\mathrm{H}_{\mathrm{a}}$ of the ISOPA unit at ca. $8.55 \mathrm{ppm}$.

\section{2. "60-Crown-20"-Based Polyrotaxanes}

The use of one "equivalent" of "60C20" ${ }^{10,11}$ led to much higher threading yields in the ISOPA-ODA polymerization (HL139, Figure 4). This is simply a result of the larger ring sizes of "60C20" vs. $30 \mathrm{C} 10$. The ring sizes are designated in terms of the total number of atoms in the ring, i. e., circumference, which is $2 \pi r(r=$ radius $)$, whereas the area of the fully opened ring in a cyclic conformation is $\pi r^{2}$. In the crystal of $30 \mathrm{C} 10$ tetrahydrate the cavity area is $7.5 \AA \times 11.4 \AA=85.5 \AA^{2} .^{12}$ Thus, the ratio of fully open cavity sizes of the 30 - vs. the 60 -membered crown ethers would be $1: 4$; that is, the cavity size of $60 \mathrm{C} 20$ would be $4\left(85.5 \AA^{2}\right)=342 \AA^{2}$. However, "60C20" is in fact a mixture of much larger macrocycles (see ESI, Figures S1-S3). ${ }^{11}$ The larger rings have more conformations than $30 \mathrm{C} 10$ and the fraction of threadable states is larger.

\section{B. Isophthalic Acid-Fluorenylidenedianiline-Based Systems}

\section{Model System and 30-Crown-10-Based Polyrotaxane}

In an attempt to increase the threading efficiency, 4,4'-(9"-fluorenylidene)dianiline (FLUODA), a more bulky, but somewhat less reactive ${ }^{13}$ commercial monomer, was used (Scheme 4). The model polymer HL58 was characterized by GPC (Table 1) and NMR spectroscopy. The ${ }^{1} \mathrm{H}$ NMR spectrum displays all the expected signals; however, the signals from the isophthalic acid moiety protons $H_{a}, H_{b}$ and $H_{c}$ shifted upfield to 8.43, 8.07 and $7.46 \mathrm{ppm}$, respectively, relative to the ODA analog. 
Figure 4 shows the ${ }^{1} \mathrm{H}$ NMR spectra of the FLUODA polymer coming from the most concentrated solution after one and two precipitations (HL88). As can be seen, the threaded and unthreaded $30 \mathrm{C} 10$ have different chemical shifts, 3.500 and 3.516 ppm, respectively. After the second precipitation, the unthreaded crown was removed. However, the amount of threaded crown decreased too.

The most concentrated solution (HL88) was cloudy even in

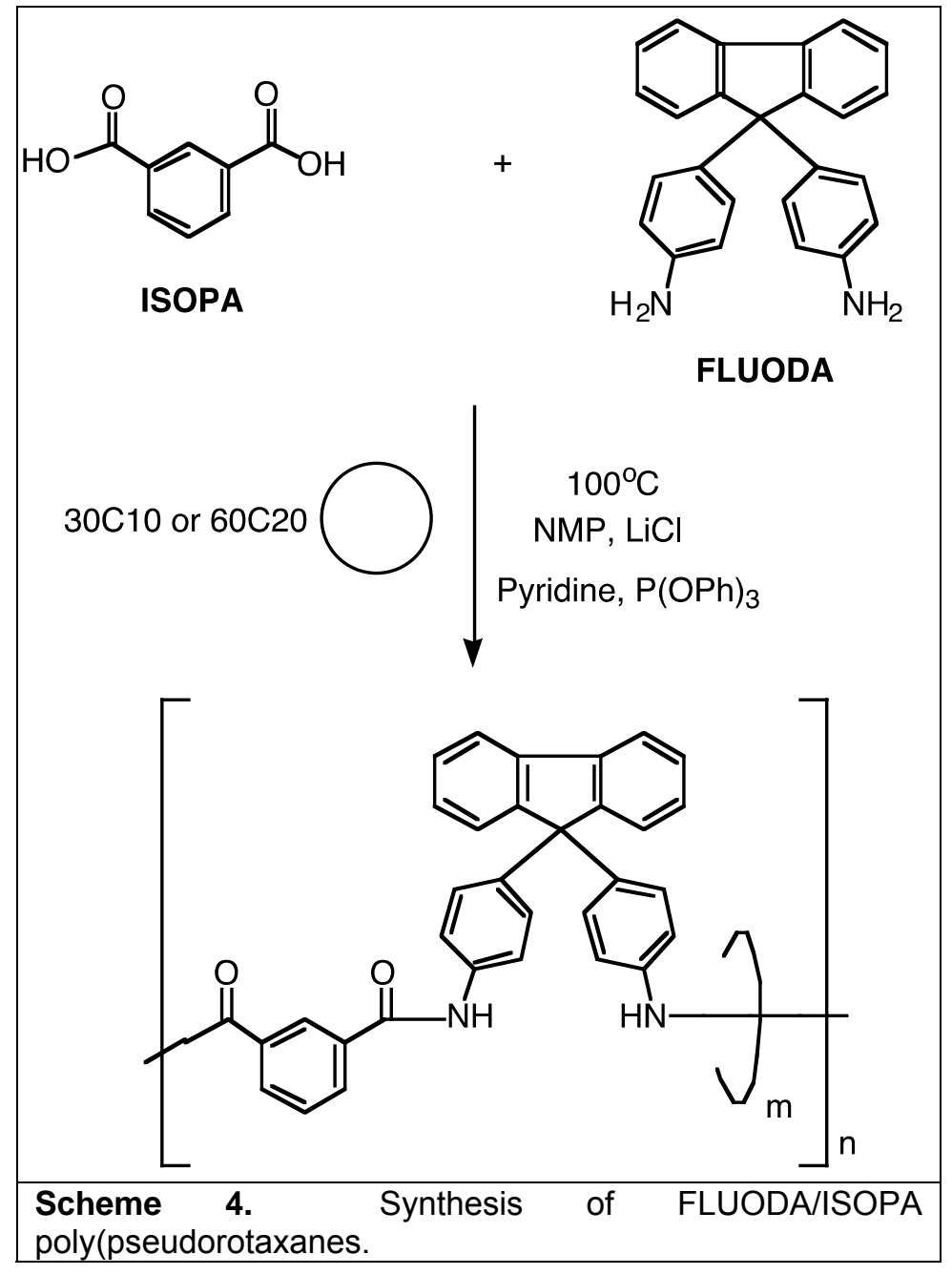
the early stage of the reaction, probably because of immiscibility of the crown with the reaction mixture. ${ }^{14}$ In a second experiment, more NMP was added at $100^{\circ} \mathrm{C}$ until complete dissolution was achieved (HL115). As can be seen in Table 1, the amount of threaded crown was higher after the second precipitation. However, the loss of crown between precipitations was higher; this can be explained by the lower molecular weight of the polymer obtained in the latter case. 


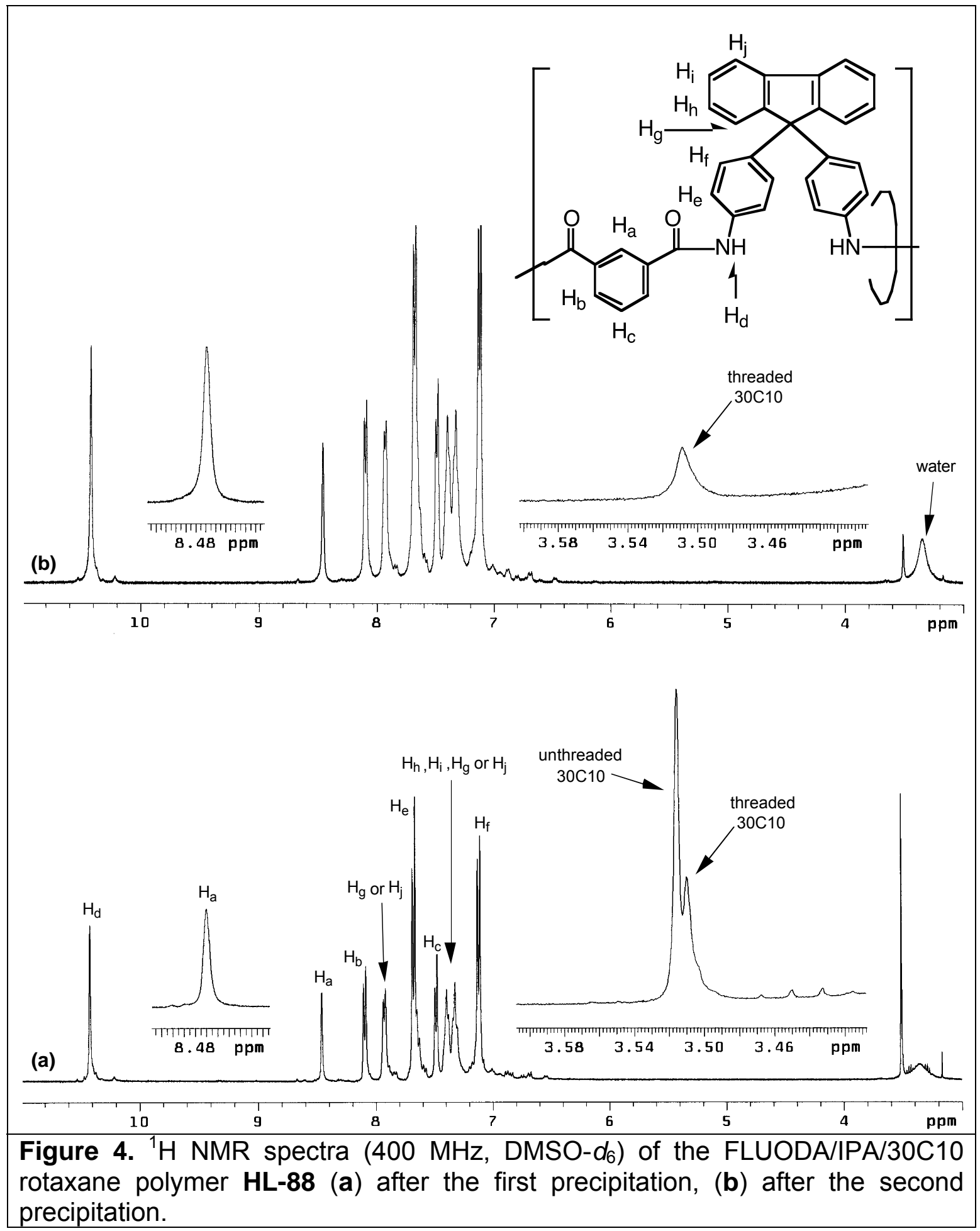


The study of these polymers by ${ }^{13} \mathrm{C} \quad \mathrm{NMR}$ (Figure 5) confirmed the formation of polyrotaxanes; the unthreaded $30 \mathrm{C} 10(69.88$ ppm) has a different chemical shift from the threaded moiety $(69.82$ ppm). In NOESY and GOESY experiments no correlation could be seen, however.

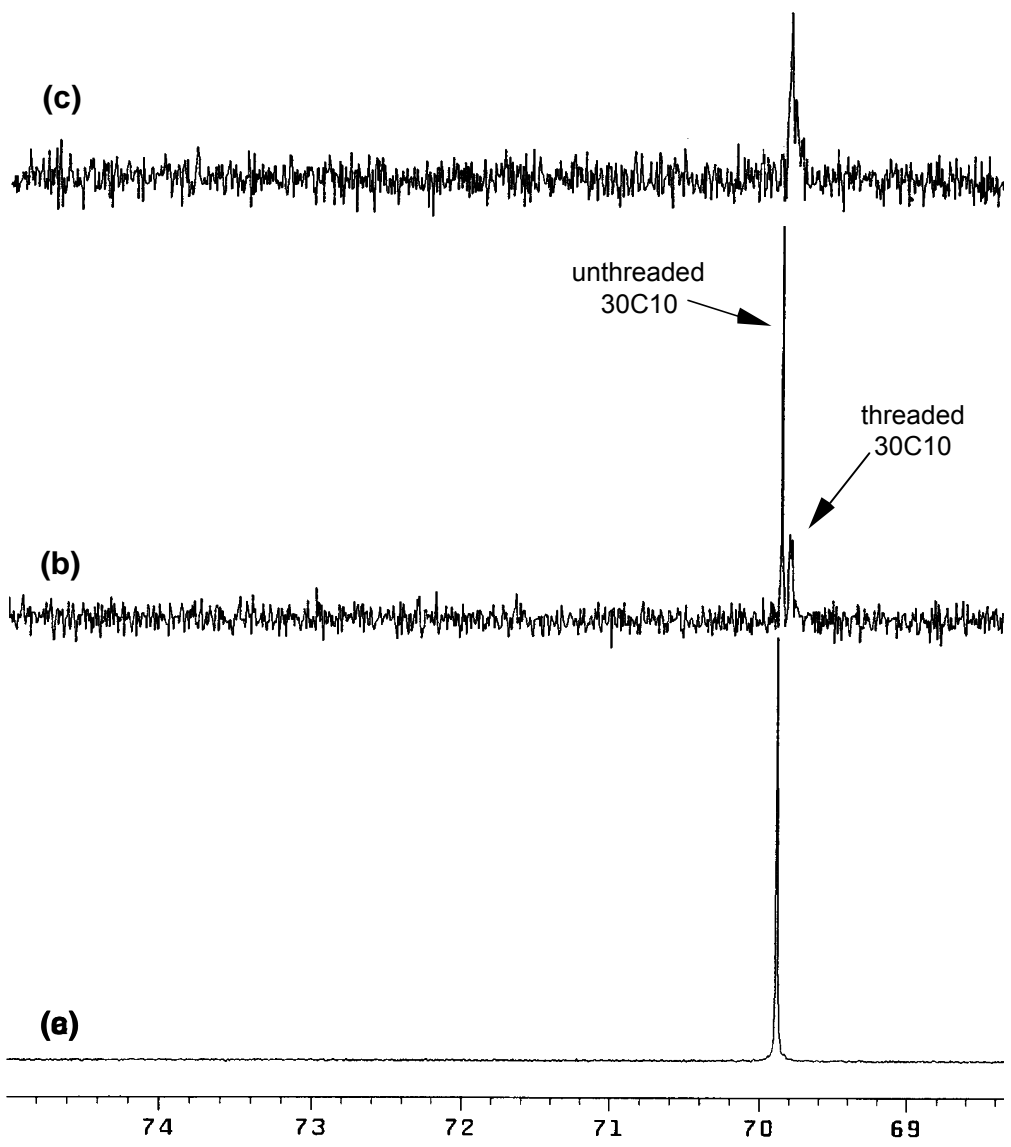

In a copolymer

Figure $5 .{ }^{13} \mathrm{C}$ NMR spectra $\left(100 \mathrm{MHz}\right.$, DMSO- $\left.d_{6}\right)$ of (a) $30 \mathrm{C} 10$, (b) the FLUODA/IPA/30C10 rotaxane polymer HL115 after the first precipitation, (c) after synthesized (HL99) with the second precipitation.

both diamines the amount

of threaded 30C10 did not change (Table 1).

\section{2. "60-Crown-20"-Based Polyrotaxane}

The use of "60C20" led to higher threading yields with the IPA/FLUODA polyamide with just a stoichiometric amount of crown (Table 1). The ${ }^{1} \mathrm{H}$ NMR spectrum of rotaxane HL137 (Figure 6) displays only one signal for the crown at $3.50 \mathrm{ppm}$. 


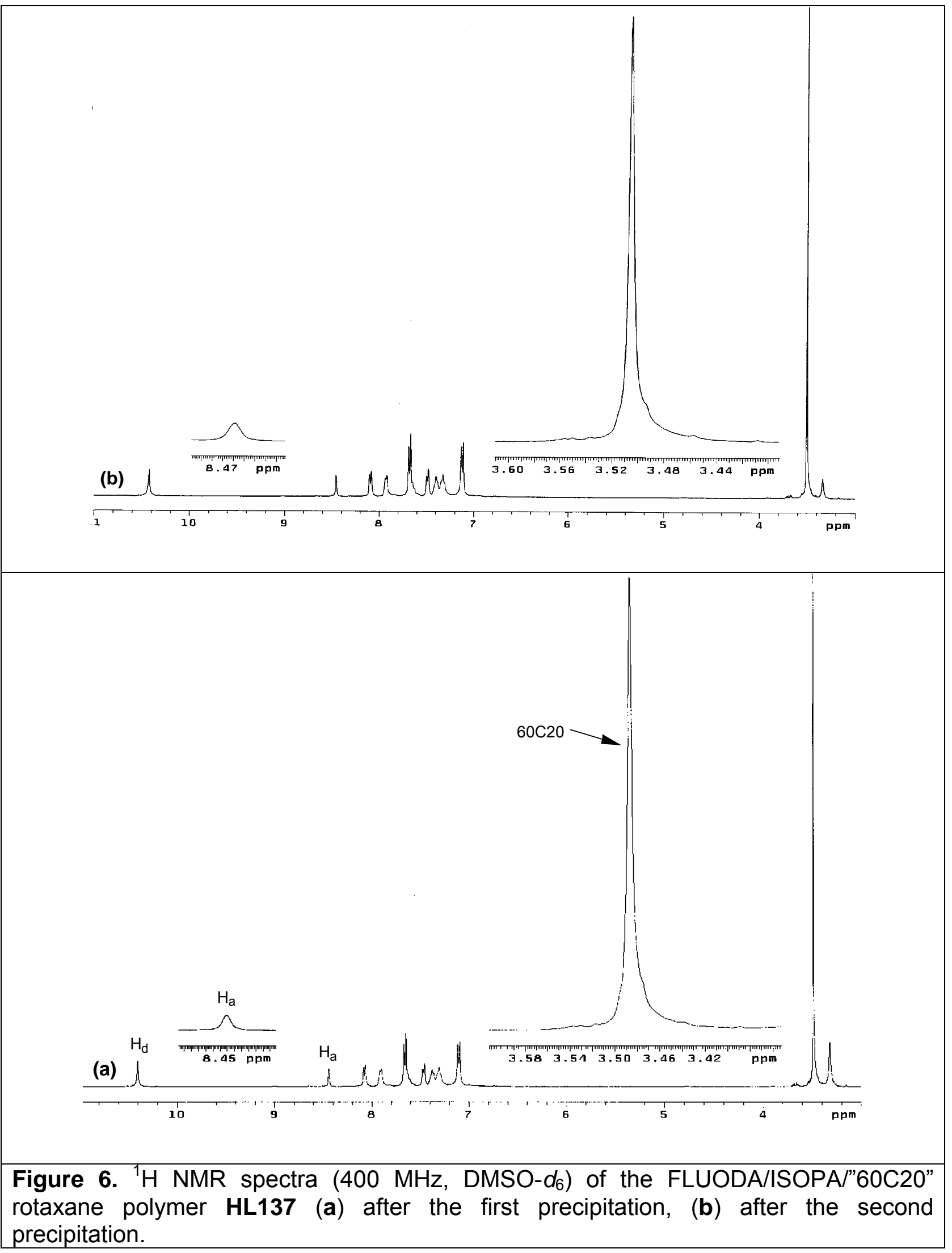


After the second precipitation the amount of crown did not change very much. The ${ }^{13} \mathrm{C}$ NMR spectrum of this polymer (Figure 7) also displays only one peak for the crown at $69.77 \mathrm{ppm}$.

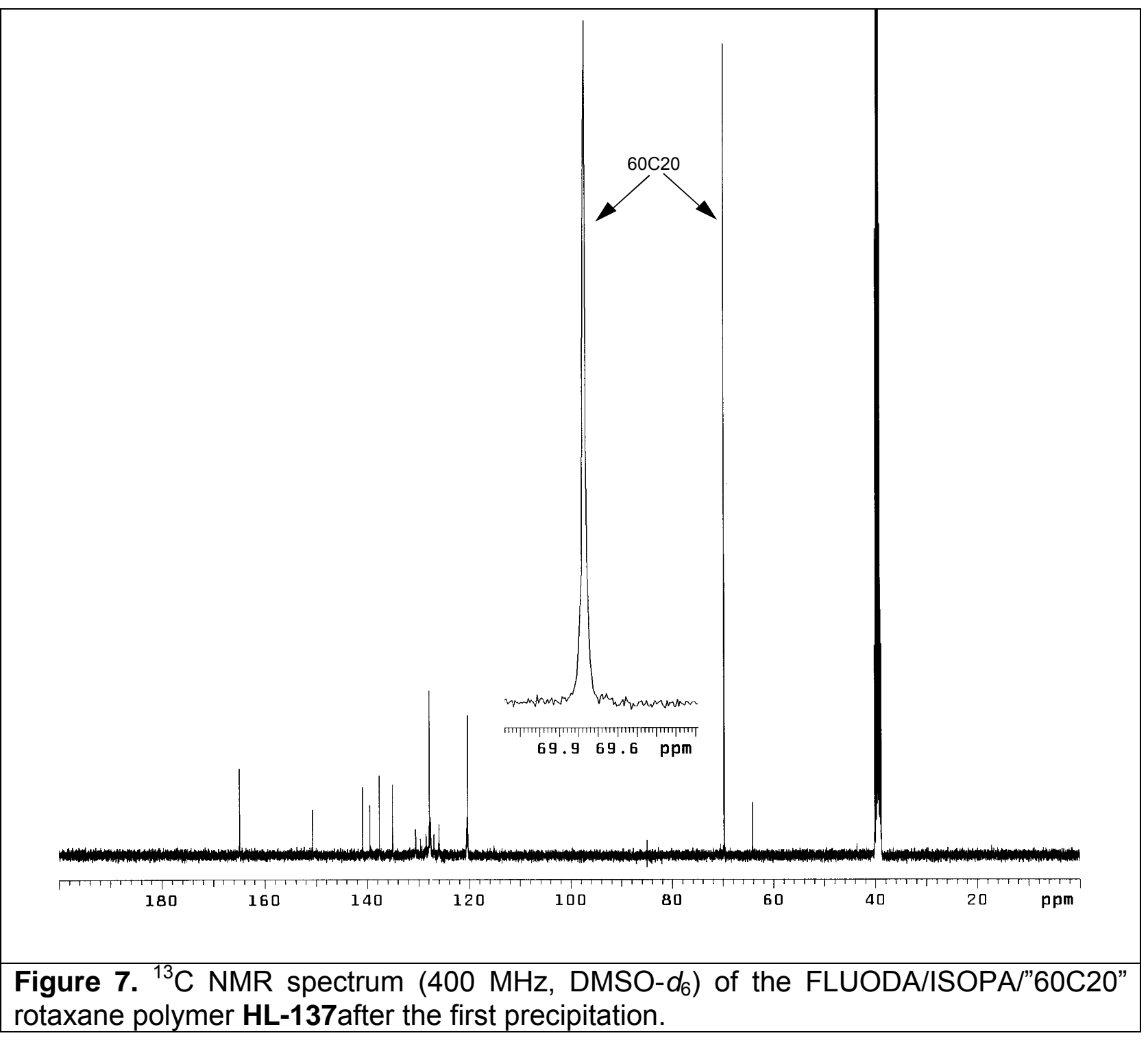

\section{Nylon-6,6-Based System}

Nylon-6,6-rotaxa-30-crown-10 was prepared from hexamethylene diamine (HMD) and adipoyl chloride using 1.28 eq of 30C10 macrocycle per monomer (Scheme 5). The model polymer was synthesized in a similar way except that diglyme was used as solvent and polymerization was done at $80-90^{\circ} \mathrm{C}$ due to the insolubility of $\mathrm{HMD}$. After 
two purifications, $\mathrm{m} / \mathrm{n}=0.024$ (4.8 weight $\%$ macrocycle) was found for the polyrotaxane (by ${ }^{1} \mathrm{H}$ NMR in trifluroacetic acid; see ESI, Figure S5). The low incorporation of macrocycle can be attributed to the low monomer to macrocycle ratio in the polymerization mixture and the small cavity size of the

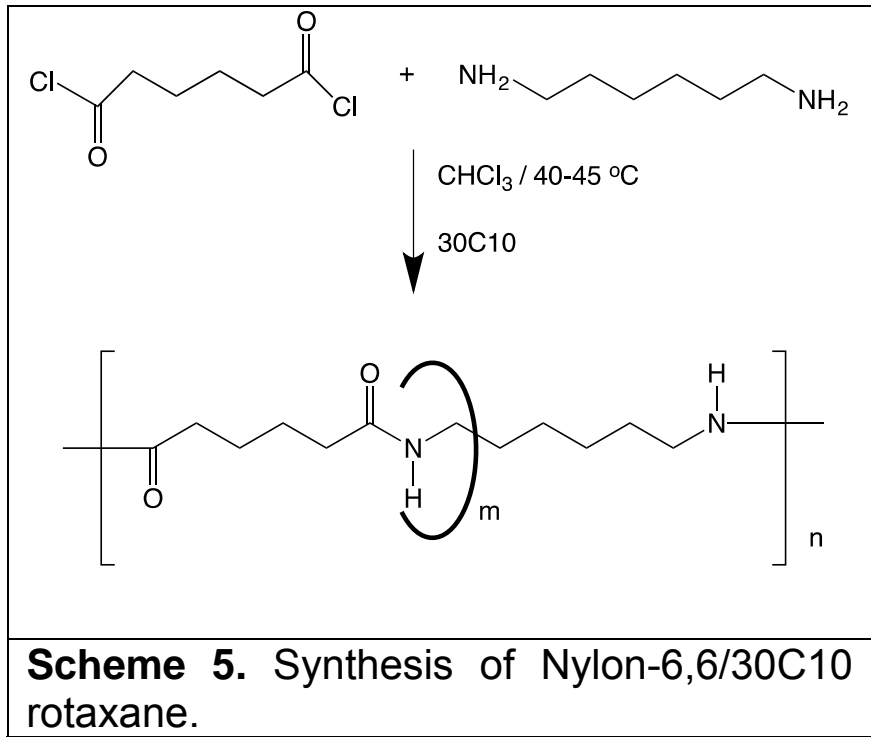

rotaxane.

macrocycle. Further, the polymerization of HMD and adipoyl chloride is very fast (less than a minute) and this may be detrimental to achieving high threading yields.

Disappointingly, the polyrotaxane did not show any changes in solubility; it was found to be insoluble in most common organic solvents, as was the model polymer.

\section{Thermal Analysis by Differential Scanning Calorimetry (DSC)}

\section{Polyaramide Rotaxanes}

Earlier in preliminary fashion we reported that polyamide rotaxanes from ODA and ISOPA displayed time dependent transition behavior. ${ }^{2 a, 2 b}$ Specifically we observed an irreversible exotherm, whose temperature increased as the solids aged over several weeks. The model polymer displayed only a glass transition at $255^{\circ} \mathrm{C}$. In the present work the DSC traces (Figure 8) of the same ODA/ISOPA/30C10 aged for 76 months (6 $1 / 3$ years) revealed an exothermic peak at $259^{\circ} \mathrm{C}$ on the first heating 
only; this compared to a peak at $181{ }^{\circ} \mathrm{C}$ immediately and $251{ }^{\circ} \mathrm{C}$ at two months post synthesis. The older ODA/ISOPA/"60C20" rotaxane polymer displayed its exotherm at $160{ }^{\circ} \mathrm{C}$ immediately and at $177^{\circ} \mathrm{C}$ after four months and in the present work after 94 months $\left(\begin{array}{lll}7 & 5 / 6 & \text { years })\end{array}\right.$ an exothermic peak at $225{ }^{\circ} \mathrm{C}$ on the first heating only (Figure 9). No transition was observed in second or third runs once the Figure 8. DSC traces of the old $(76 \mathrm{mo}$.) ODA/ISOPA/30C10 rotaxane polymer after the third precipitation from DMSO.

exotherm was observed.

Depending on the
solvent used for the
precipitation, the present
ODA/ISOPA/30C10 polymers
displayed different behaviors
(Figure 10). When the polymer
was precipitated in methanol
from DMSO, a large exothermic
peak was observed at $255{ }^{\circ} \mathrm{C}$
on the first heating only.

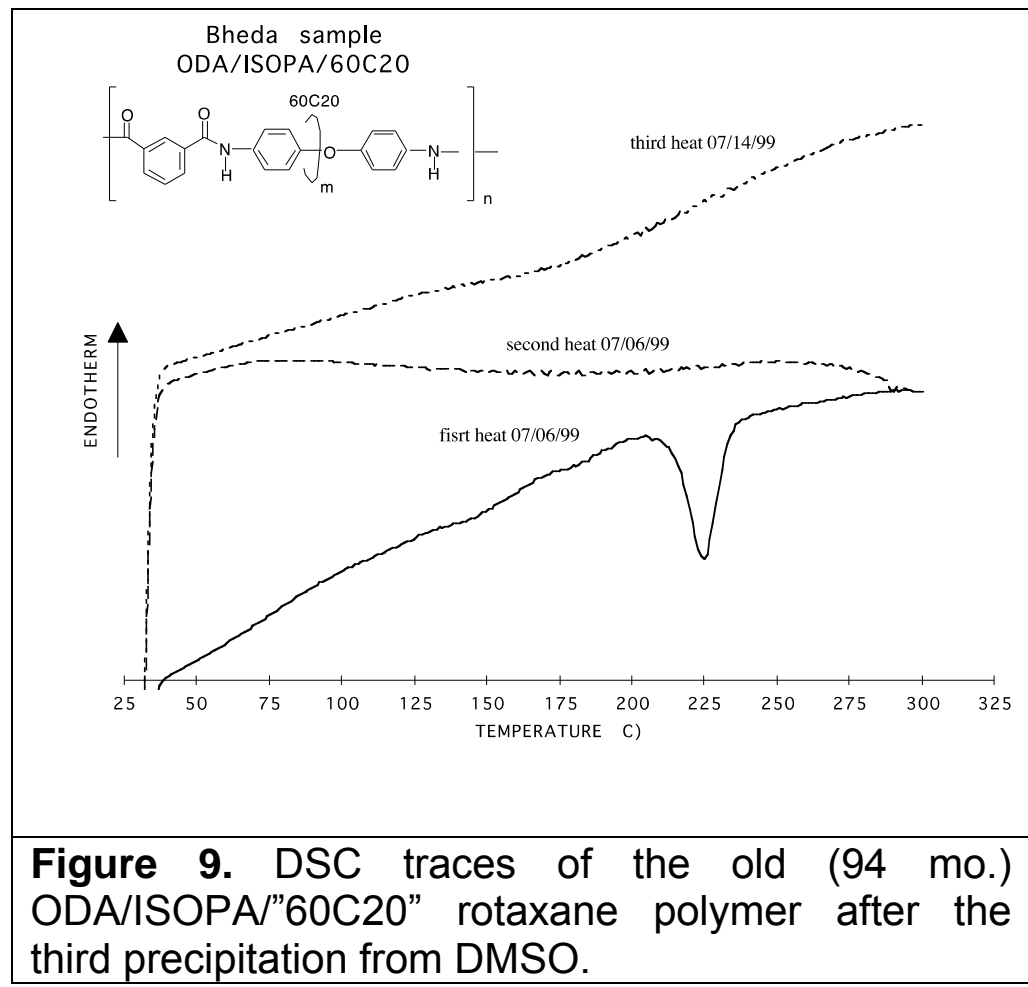


The ODA/ISOPA/"60C20"

rotaxane polymer behaves in the same manner (Figure 11). An exothermic peak was observed at $282{ }^{\circ} \mathrm{C}$ when the polymer was precipitated from DMF into methanol. For the other solvents, only waves were observed; these may arise from residual water and solvent.

No transitions were observed in DSC traces

of the FLUODA/ISOPA model polymer,

the

FLUODA/ISOPA/30C10 or the FLUODA/IPA/"60C20"

polyrotaxanes (ESI, Figures S6 and S7).

It was originally suggested $2 a, 2 b$ that the time dependent exotherms observed were due to reorganization in the solid state; specifically it was suggested that intraannular hydrogen bonding of the crown ethers to the $\mathrm{NH}$ moieties of the backbone were locked in during the precipitation process and the transition corresponded to the 
breakup of this interaction and its replacement by stronger ${ }^{15}$ intermolecular $\mathrm{NH}---\mathrm{O}=\mathrm{C}$ bonds. ${ }^{2 \mathrm{a}, 2 \mathrm{~b}}$ However, the present results differ in that the temperature of the transition did not vary with time; high transition temperatures were observed on freshly prepared samples. The exothermic transition may be preceded by an incipient glass transition that is dependent on the dryness of the polymer. It is known that polyaramides absorb $\sim 5 \%$ water. $^{16}$ The earlier samples were dried in vacuo at room temperature for 36 hours and then stored under ambient conditions, while the present samples were dried in vacuo at room temperature for several days. The longer drying process probably resulted in a lower water/methanol content, thus increasing the incipient $T_{g}$ and consequent exotherm temperature relative to the earlier samples.

In the case of the FLUODA polymers the bulky amine moiety probably restricts the mobility of threaded crown ethers, confining them to the ODA segment preferentially and disallowing such a solid state ordering process.

\section{Nylon-6,6 Rotaxane}

The glass transition temperature $\left(T_{g}\right.$, reported $\left.65^{\circ} \mathrm{C}^{16}\right)$ for the model Nylon-6,6 was not clearly observed either in the first or second heatings. In the second heating a melting transition, $\mathrm{T}_{\mathrm{m}}$, appeared as a strong exotherm at $243^{\circ} \mathrm{C}(\mathrm{SI}$, Figure S8; reported $\mathrm{T}_{\mathrm{m}}=265^{\circ} \mathrm{C}{ }^{17}$ ). The polyrotaxane showed a broad melting peak from $212-249{ }^{\circ} \mathrm{C}$, with a maximum at $240^{\circ} \mathrm{C}(\mathrm{ESI}$, Figure S9).

\section{CONCLUSIONS}


We thought that the threading efficiencies of these polyamides would be better than those with polyester rotaxanes, since after reaction hydrogen bonding between crown ethers and $\mathrm{NH}$ moieties in the polyamide backbone main chain can still take place (as demonstrated with polyurethanes both through infrared studies, ${ }^{4 b}$ that yielded an average enthalpy of $3 \mathrm{kcal} / \mathrm{mol}$, and by threading of preformed polymers ${ }^{4 \mathrm{~g}}$ ), while in polyesters there is no such possibility; however, the amounts of $30 \mathrm{C} 10$ in the final polyamides (Table 1) are less than in the aliphatic polyesters, depending on the synthetic method (Table 2). ${ }^{3}$ For example, transesterifications of dimethyl sebacate with butylene glycol in the presence of 30-crown-10 or "60-crown-20" (PE1, PE2) afforded $\mathrm{m} / \mathrm{n}$ values of 0.13 and 0.30 , while tri(ethylene glycol) under the same conditions (PE3, PE4) led to even higher values. In contrast, reactions of sebacoyl chloride with decamethylene glycol in the presence of of 30-crown-10 (PE6) or "60-crown-20" (PE7) afforded lower $\mathrm{m} / \mathrm{n}$ values, except when a bulky end-capper was used (PE5). ${ }^{3 a, 3 b}$ Employment of a bulky diol with sebacoyl chloride resulted in surprisingly low $\mathrm{m} / \mathrm{n}$ values (PE8, PE9), but use of a bulky diol and a bulky diacid chloride in the presence of 30-crown-10 (PE-10) afforded an $\mathrm{m} / \mathrm{n}$ value of 0.172 , demonstrating that most of the initially threaded macrocycle is lost prior to isolation of the polymer. In aliphatic polyurethanes the incorporation of "60-crown-20" was facile, leading to very high $\mathrm{m} / \mathrm{n}$ values (PU1, PU2), due to strong hydrogen bonding interactions. ${ }^{4 b}$

Indeed, the present $\mathrm{m} / \mathrm{n}$ values for $30 \mathrm{C} 10$ systems (Table 1 ) are closer to those 


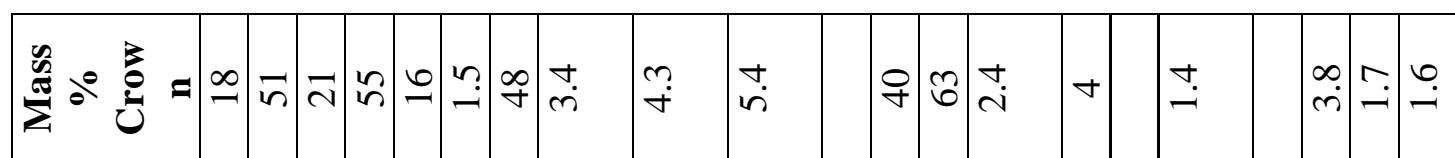

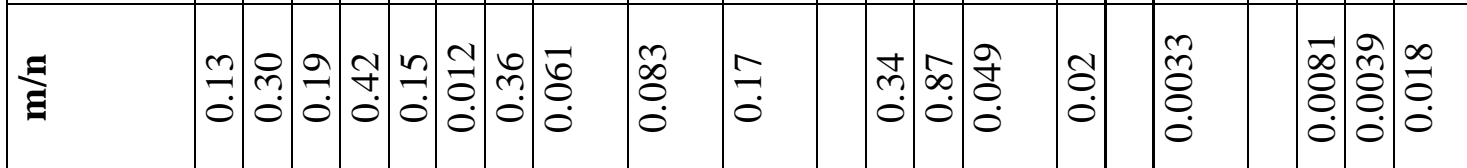

艾要

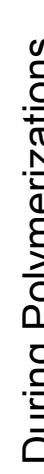

后亭

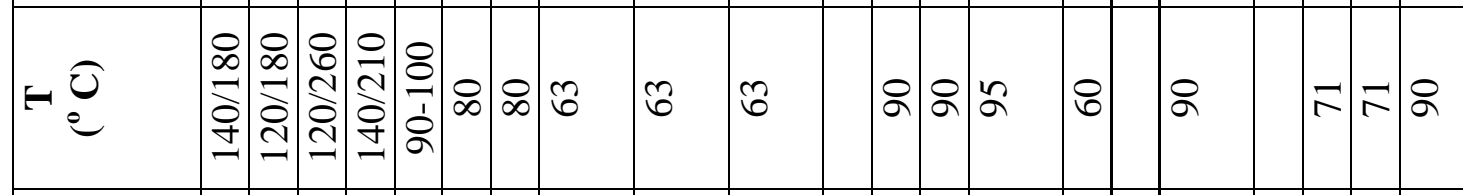

읻

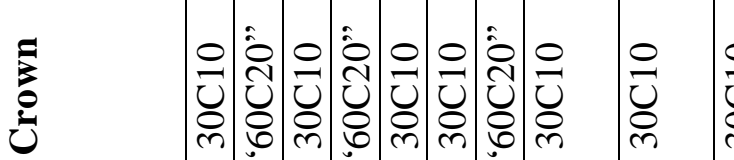

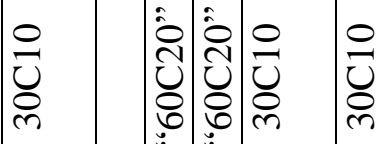

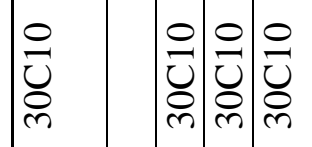

ชิ

$\stackrel{8}{\circ}$

ভั

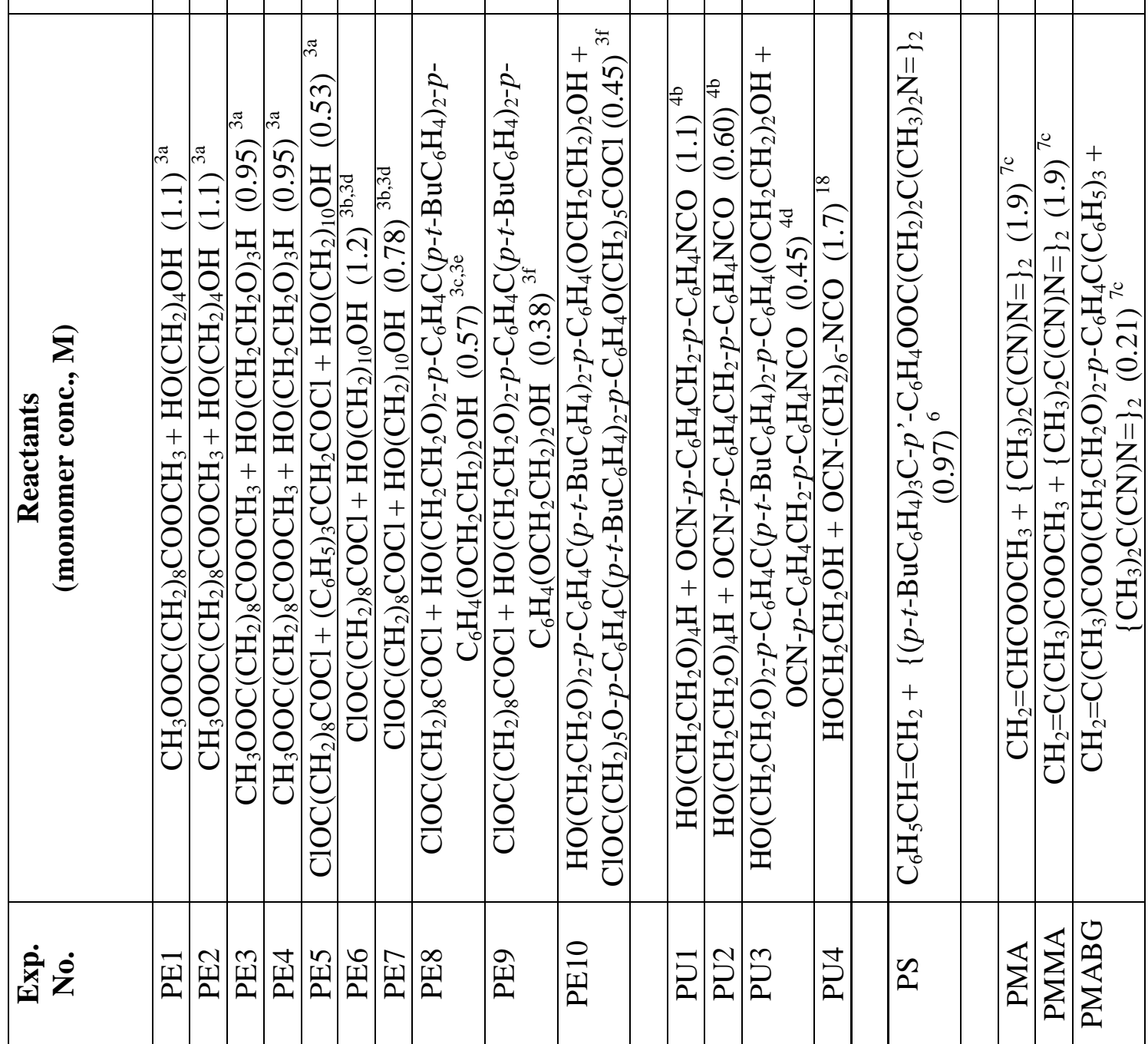


observed in free radical polymerizations of styrene (PS), methyl acrylate (PMA), methyl methacrylate (PMMA) and a methacrylate with a long bulky ester moiety (PMMABG) in the presence of 30-crown-10 (Table 2). However, a major difference in the present case is the highly polar reaction medium containing NMP, pyridine and LiCl. The polar medium hinders hydrogen-bonding interactions between the crown ethers and the monomers and the amide linkages of the polymers. Moreover, the lithium cation also complexes strongly with the crown ethers, ${ }^{19}$ further inhibiting their interactions with the monomers and amide linkages. And the concentrations of monomers and thus crown ethers were lower in the present work (Table 1) than for the polyesters and polyurethanes in Table 2 .

In summary, polyaramide $30 \mathrm{C} 10$ and "60C20" rotaxanes were prepared from ODA and FLUODA with ISOPA; a Nylon-6,6 rotaxane was also synthesized using $30 \mathrm{C} 10$. In general the extent of incorporation of threaded $30 \mathrm{C} 10$ in these polyamides was low relative to previous results with polyesters and polyurethanes; however, use of the larger mixture of crown ethers, "60C20", did lead to significant incorporation into the resultant polyaramides. An interesting solid-state reorganization of the ODA/ISOPA rotaxanes found earlier was confirmed in this work.

\section{ACKNOWLEDGMENTS}

The authors thank the National Science Foundation for funding this work via grants DMR 90-15729, DMR 93-20196 and DMR 97-06909, Dr. Qing Ji in the late Prof. James E. McGrath's group for the GPC data and Dr. Abaneshwar Prasad in Prof. Herve' Marand's laboratory and Mr. Paul Vail in Prof. Thomas C. Ward's group for some of the DSC results. We thank the Washington University Resource for Biomedical and Bioi-organic Mass Spectrometry for the electrospray ionization MS of "60C20"; that 
resource is supported by grants form the National Institute of General Medical Sciences (8 P41 GM103422) from the National Institutes of Health.

\section{EXPERIMENTAL}

Materials. Unless specified otherwise, reagent-grade reactants and solvents were used as received from chemical suppliers. Pyridine and NMP were dried and distilled from $\mathrm{CaH}_{2}$ and stored over molecular sieves. THF was dried and distilled from $\mathrm{Na}$ /benzophenone. Chloroform was dried and distilled from $\mathrm{P}_{2} \mathrm{O}_{5} .30-$-Crown-10 and "60crown-20" were prepared as previously reported ${ }^{19}$ and described in the ESI. $\mathrm{LiCl}$, ISOPA, ODA, FLUODA, 30C10 and "60-crown-20" were dried in vacuum at room temperature over $\mathrm{P}_{2} \mathrm{O}_{5}$ before use. Hexamethylenediamine (HMD, $99 \%$ ) was purified by sublimation under vacuum at $35-40{ }^{\circ} \mathrm{C}$; mp $43-44{ }^{\circ} \mathrm{C}$ (corr.); reported mp $41-42{ }^{\circ} \mathrm{C},{ }^{20} 42$ ${ }^{\circ} \mathrm{C} .{ }^{21}$ Adipoyl chloride was purified by two vacuum distillations, bp $113-115^{\circ} \mathrm{C} / 2-3$ Torr; reported bp $126{ }^{\circ} \mathrm{C} / 12$ Torr. $^{22}$ To clearly integrate the crown ether peaks in the ${ }^{1} \mathrm{H}$ NMR spectra of the polyaramides DMSO- $d_{6}$ was carefully dried with $\mathrm{P}_{2} \mathrm{O}_{5}$ to remove the water peak at $3.33 \mathrm{ppm}$.

Measurements. The ${ }^{1} \mathrm{H}$ NMR spectra were obtained at ambient temperature on a Bruker WP $270 \mathrm{MHz}$ or a Varian Unity $400 \mathrm{MHz}$ spectrometer in DMSO-d $d_{6}$ or $\mathrm{CF}_{3} \mathrm{COOD}$ with TMS ( $=0.0 \mathrm{ppm})$ as internal standard. The thermal properties were obtained on a DuPont 2100 or a Perkin-Elmer DSC-4 at a rate of $20^{\circ} \mathrm{C} / \mathrm{min}$; melting transitions were taken as the minima of the melting endotherm and $T_{g}$ as the midpoint of the heat capacity change. All samples were first heated at a rate of 10 or $20^{\circ} \mathrm{C} / \mathrm{min}$ to $120^{\circ} \mathrm{C}$ in order to remove water traces. The absolute molecular weights of the polymers were measured by GPC in NMP containing $20 \mathrm{mM} \mathrm{P} \mathrm{O}_{5}$ at $60{ }^{\circ} \mathrm{C}$ using a Waters 2690 separations module equipped with a differential refractometer and an on-line differential 
viscosimetric detector (Viscotek T60A dual detector) coupled in parallel and the universal calibration was used. The melting point was taken in a capillary tube with a Melt-Temp II apparatus.

ODA/ISOPA model polymer HL33: ISOPA (0.224 g, $1.35 \mathrm{mmol}), 0.2700 \mathrm{~g}(1.35 \mathrm{mmol})$ of ODA, $0.77 \mathrm{~mL}(5.4 \mathrm{mmol})$ of diglyme, $0.75 \mathrm{~mL}(9.2 \mathrm{mmol})$ of pyridine, $1.25 \mathrm{ml}$ of NMP and $0.2 \mathrm{~g}(5 \mathrm{mmol})$ of $\mathrm{LiCl}$ were mixed under nitrogen and heated at $100{ }^{\circ} \mathrm{C}$. To this, $0.71 \mathrm{~mL}(2.7 \mathrm{mmol})$ of triphenylphosphite was added. After $1 \mathrm{~h}$, the solution became viscous and some precipitation occurred, so $2 \mathrm{~mL}$ of dry NMP were added and the polymerization was continued overnight. The reaction mixture was precipitated into 200 $\mathrm{mL}$ of methanol; the colorless solid was filtered and dried at room temperature under vacuum for several days $(0.5 \mathrm{~g}) .{ }^{1} \mathrm{H}$ NMR (DMSO- $\left.d_{6}\right)$ : $10.44(\mathrm{~s}, 2 \mathrm{H}), 8.51(\mathrm{~s}, 1 \mathrm{H})$, $8.13(\mathrm{~d}, \mathrm{~J}=8 \mathrm{~Hz}, 2 \mathrm{H}), 7.79(\mathrm{~d}, \mathrm{~J}=9 \mathrm{~Hz}, 4 \mathrm{H}), 7.67(\mathrm{t}, \mathrm{J}=8 \mathrm{~Hz}, 1 \mathrm{H}), 7.03(\mathrm{~d}, J=9 \mathrm{~Hz}$ $4 \mathrm{H})$.

ODA/ISOPA/30C10 rotaxane HL31: ISOPA $(0.224 \mathrm{~g}, 1.35 \mathrm{mmol}), 0.2700 \mathrm{~g}(1.35$ $\mathrm{mmol})$ of ODA, $2.5300 \mathrm{~g}(5.75 \mathrm{mmol})$ of $30 \mathrm{C} 10,0.75 \mathrm{~mL}(9.2 \mathrm{mmol})$ of pyridine, 1.25 $\mathrm{mL}$ of NMP and $0.2 \mathrm{~g} \mathrm{(5} \mathrm{mmol)} \mathrm{of} \mathrm{LiCl}$ were mixed under nitrogen and heated at $100^{\circ} \mathrm{C}$ for $30 \mathrm{~min}$. To this, $0.71 \mathrm{~mL}(2.7 \mathrm{mmol})$ of triphenylphosphite were added and the polymerization was continued for $24 \mathrm{~h}$. The reaction mixture was precipitated into 200 $\mathrm{mL}$ of methanol and the colorless solid was filtered and washed with methanol and dried at room temperature under vacuum for several days $(0.75 \mathrm{~g})$. The polymer was dissolved in the minimum volume of NMP and precipitated into $>10 \mathrm{X}$ the volume of methanol and dried at room temperature under vacuum for several days $(0.33 \mathrm{~g}) .{ }^{1} \mathrm{H}$ NMR (DMSO-d $\left.)_{6}\right): 10.45(\mathrm{~s}, 2 \mathrm{H}), 8.53(\mathrm{~s}, 1 \mathrm{H}), 8.13(\mathrm{~d}, \mathrm{~J}=8 \mathrm{~Hz}, 2 \mathrm{H}), 7.80$ (d, J = $9 \mathrm{~Hz}$, 
4H), $7.68(\mathrm{t}, J=8 \mathrm{~Hz}, 1 \mathrm{H}), 7.04(\mathrm{~d}, J=9 \mathrm{~Hz}, 4 \mathrm{H}), 3.516$ (s, unthreaded 30C10), 3.505 (s, threaded 30C10).

ODA/ISOPA/30C10 rotaxane HL51: ISOPA (0.166 g, $1.00 \mathrm{mmol}), 0.200 \mathrm{~g}(1.00 \mathrm{mmol})$

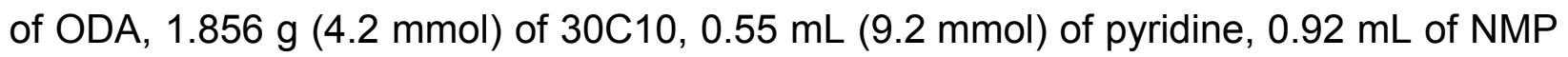
and $0.146 \mathrm{~g}(3.48 \mathrm{mmol})$ of $\mathrm{LiCl}$ were mixed under nitrogen and heated at $100^{\circ} \mathrm{C}$ for 30 min. To this, $0.53 \mathrm{~mL}(2.0 \mathrm{mmol})$ of triphenylphosphite were added and the polymerization was continued for $24 \mathrm{~h}$. The reaction mixture was diluted with $10 \mathrm{~mL}$ of NMP and precipitated into $150 \mathrm{~mL}$ of methanol; the colorless solid was filtered and washed with methanol and dried under vacuum at room temperature for several days $(0.36 \mathrm{~g})$. The polymer $(200 \mathrm{mg})$ was dissolved in $5 \mathrm{~mL}$ of NMP and precipitated into 200 $\mathrm{mL}$ of methanol and dried at room temperature under vacuum for several days.

FLUODA/ISOPA model polymer HL58: ISOPA (0.166 g, $1.00 \mathrm{mmol}), 0.348 \mathrm{~g}(1.00$ $\mathrm{mmol})$ of FLUODA, $0.55 \mathrm{~mL}(6.8 \mathrm{mmol})$ of pyridine, $0.92 \mathrm{ml}$ of NMP and $0.146 \mathrm{~g}(3.48$ $\mathrm{mmol})$ of $\mathrm{LiCl}$ were mixed under nitrogen and heated at $100{ }^{\circ} \mathrm{C}$. To this, $0.53 \mathrm{~mL}(2.0$ $\mathrm{mmol}$ ) of triphenylphosphite were added. After $3 \mathrm{~h}$, precipitation occurred, so $3 \mathrm{~mL}$ of dry NMP were added, everything dissolved and the polymerization was continued overnight. The reaction mixture was precipitated into $200 \mathrm{~mL}$ of methanol. The colorless polymer was filtered and dried at room temperature under vacuum for several days, 0.5 g. ${ }^{1} \mathrm{H}$ NMR (DMSO- $\left.d_{6}\right): 10.39(\mathrm{~s}, 2 \mathrm{H}), 8.43(\mathrm{~s}, 1 \mathrm{H}), 8.07$ (d, $\left.\mathrm{J}=8 \mathrm{~Hz}, 2 \mathrm{H}\right), 7.91$ (d, $J=7$ $\mathrm{Hz}, 2 \mathrm{H}), 7.65(\mathrm{~d}, \mathrm{~J}=9 \mathrm{~Hz}, 4 \mathrm{H}), 7.46(\mathrm{t}, \mathrm{J}=8 \mathrm{~Hz}, 1 \mathrm{H}), 7.2-7.4(\mathrm{~m}, 6 \mathrm{H}), 7.10(\mathrm{~d}, \mathrm{~J}=9 \mathrm{~Hz}$, $4 \mathrm{H})$.

FLUODA/ISOPA/30C10 rotaxane polymer HL88: ISOPA (0.166 g, $1.00 \mathrm{mmol}), 0.348$ $\mathrm{g}(1.00 \mathrm{mmol})$ of FLUODA, $0.55 \mathrm{~mL}(6.8 \mathrm{mmol})$ of pyridine, $0.92 \mathrm{ml}$ of NMP, $1.76 \mathrm{~g}$ $(4.00 \mathrm{mmol})$ of $30 \mathrm{C} 10$, and $0.146 \mathrm{~g}(3.48 \mathrm{mmol})$ of $\mathrm{LiCl}$ were mixed under nitrogen and 
heated at $100{ }^{\circ} \mathrm{C}$. To this, $0.53 \mathrm{~mL}(2.0 \mathrm{mmol})$ of triphenylphosphite were added. The polymerization was continued overnight. The reaction mixture was precipitated into 200 $\mathrm{mL}$ of methanol. The colorless polymer was filtered and dried at room temperature under vacuum for several days, $0.5 \mathrm{~g}$. The polymer was dissolved in the minimum volume of NMP and precipitated into 10X the volume of methanol; this process was repeated to produce the third precipitate. The polymer was dried at room temperature under vacuum for several days after each precipitation. ${ }^{1} \mathrm{H}$ NMR (DMSO- $\left.d_{6}\right): 10.41$ (s, 2H), $8.45(\mathrm{~s}, 1 \mathrm{H}), 8.10(\mathrm{~d}, J=8 \mathrm{~Hz}, 2 \mathrm{H}), 7.94(\mathrm{~d}, J=7 \mathrm{~Hz}, 2 \mathrm{H}), 7.67(\mathrm{~d}, J=9 \mathrm{~Hz}, 4 \mathrm{H})$, $7.48(\mathrm{~d}, \mathrm{~J}=8,1 \mathrm{H}), 7.2-7.4(\mathrm{~m}, 6 \mathrm{H}), 7.11(\mathrm{~d}, \mathrm{~J}=9 \mathrm{~Hz}, 4 \mathrm{H}), 3.516$ (s, unthreaded 30C10), 3.510 (s, threaded 30C10).

ODA/FLUODA/ISOPA/30C10 rotaxane copolymer HL99: ISOPA (0.166 g, 1.00 $\mathrm{mmol}), 0.1605 \mathrm{~g}(0.8025 \mathrm{mmol})$ of ODA, $0.0687 \mathrm{~g}(0.298 \mathrm{mmol})$ of FLUODA, $0.55 \mathrm{~mL}$ $(6.8 \mathrm{mmol})$ of pyridine, $0.92 \mathrm{ml}$ of NMP, $1.787 \mathrm{~g}(4.06 \mathrm{mmol})$ of $30 \mathrm{C} 10$, and $0.146 \mathrm{~g}$ (3.48 mmol) of $\mathrm{LiCl}$ were mixed under nitrogen and heated at $100{ }^{\circ} \mathrm{C}$. To this, $0.53 \mathrm{~mL}$ (2.0 mmol) of triphenylphosphite were added, producing a cloudy mixture. The polymerization was continued overnight. The mixture was precipitated into $200 \mathrm{~mL}$ of methanol; the polymer was filtered and washed with methanol and dried at room temperature under vacuum for several days $(0.40 \mathrm{~g})$. The polymer was dissolved in the minimum volume of NMP and precipitated into $>10 \mathrm{X}$ that volume of methanol; this process was repeated to produce a third precipitated sample. The colorless polymer was dried at room temperature under vacuum for several days after each precipitation. ${ }^{1} \mathrm{H}$ NMR (DMSO-d $\left.\mathrm{d}_{6}\right): 10.45$ (s, 2H), 8.53 (s, 0.68), 8.49 (s, 0.32H), 8.14 (b m, 2H), 7.93 (d, 0.64H), $7.81(d, J=9 \mathrm{~Hz}, 1.36 \mathrm{H}), 7.69(\mathrm{~d}, \mathrm{~J}=9 \mathrm{~Hz}, 0.68 \mathrm{H}), 7.49$ (b s, 0.64H), 7.4- 
$7.2(\mathrm{~b} \mathrm{~m}, 1.92 \mathrm{H}), 7.13(\mathrm{~d}, \mathrm{~J}=9 \mathrm{~Hz}, 1.28 \mathrm{H}), 7.05(\mathrm{~d}, \mathrm{~J}=9 \mathrm{~Hz}, 1.36 \mathrm{H}), 3.516(\mathrm{~s}$, unthreaded 30C10), 3.510 (s, threaded 30C10).

ODA/FLUODA/ISOPA model copolymer HL-101: ISOPA (0.166 g, $1.00 \mathrm{mmol})$, $0.1605 \mathrm{~g}(0.8025 \mathrm{mmol})$ of ODA, $0.0687 \mathrm{~g}(0.298 \mathrm{mmol})$ of FLUODA, $0.55 \mathrm{~mL}(6.8$ $\mathrm{mmol})$ of pyridine, $0.92 \mathrm{ml}$ of NMP and $0.146 \mathrm{~g}(3.48 \mathrm{mmol})$ of $\mathrm{LiCl}$ were mixed under nitrogen and heated at $100{ }^{\circ} \mathrm{C}$. To this, $0.53 \mathrm{~mL}(2.0 \mathrm{mmol})$ of triphenylphosphite were added. The polymerization was continued overnight. The mixture was precipitated into $200 \mathrm{~mL}$ of methanol; the colorless polymer was filtered and washed with methanol and dried at room temperature under vacuum for several days $(0.37 \mathrm{~g}) .{ }^{1} \mathrm{H}$ NMR (DMSO- $\left.d_{6}\right)$ : 10.45 (s, 2H), $8.53(\mathrm{~s}, 0.68), 8.49(\mathrm{~s}, 0.32 \mathrm{H}), 8.14(\mathrm{~b} \mathrm{~m}, 2 \mathrm{H}), 7.93(\mathrm{~d}, 0.64 \mathrm{H}), 7.81(\mathrm{~d}, \mathrm{~J}$ $=9 \mathrm{~Hz}, 1.36 \mathrm{H}), 7.69(\mathrm{~d}, \mathrm{~J}=9 \mathrm{~Hz}, 0.68 \mathrm{H}), 7.49(\mathrm{~b} \mathrm{~s}, 0.64 \mathrm{H}), 7.4-7.2(\mathrm{~b} \mathrm{~m}, 1.92 \mathrm{H}), 7.13$ $(\mathrm{d}, J=9 \mathrm{~Hz}, 1.28 \mathrm{H}), 7.05(\mathrm{~d}, J=9 \mathrm{~Hz}, 1.36 \mathrm{H})$.

FLUODA/ISOPA/30C10 rotaxane polymer HL115: ISOPA (0.166 g, $1.00 \mathrm{mmol}), 0.348$ $\mathrm{g}(1.00 \mathrm{mmol})$ of FLUODA, $0.55 \mathrm{~mL}(6.8 \mathrm{mmol})$ of pyridine, $3.4 \mathrm{ml}$ of NMP, $1.76 \mathrm{~g}(4.00$ $\mathrm{mmol})$ of $30 \mathrm{C} 10$, and $0.146 \mathrm{~g}(3.48 \mathrm{mmol})$ of $\mathrm{LiCl}$ were mixed under nitrogen and heated at $100{ }^{\circ} \mathrm{C}$. To this, $0.53 \mathrm{~mL}(2.0 \mathrm{mmol})$ of triphenylphosphite were added. The polymerization was continued overnight. The cloudy mixture was treated with $5 \mathrm{~mL}$ of NMP to dissolve everything and this solution was precipitated into $200 \mathrm{~mL}$ of methanol; the colorless polymer was filtered and washed with methanol. The polymer was dissolved in the minimum volume of NMP $(5 \mathrm{~mL})$ and precipitated into $100 \mathrm{~mL}$ of methanol. The colorless polymer was dried at room temperature under vacuum for several days after each precipitation.

ODA/ISOPA/30C10 rotaxane HL121: ISOPA (0.166 g, $1.00 \mathrm{mmol}), 0.200 \mathrm{~g}(1.00$ $\mathrm{mmol})$ of ODA, $1.76 \mathrm{~g}(4.0 \mathrm{mmol})$ of $30 \mathrm{C} 10,0.56 \mathrm{~mL}(9.2 \mathrm{mmol})$ of pyridine, $3.6 \mathrm{~mL}$ of 
NMP and $0.176 \mathrm{~g}(3.48 \mathrm{mmol})$ of $\mathrm{LiCl}$ were mixed under nitrogen and heated at $100^{\circ} \mathrm{C}$ for $30 \mathrm{~min}$. To this, $0.53 \mathrm{~mL}(2.0 \mathrm{mmol})$ of triphenylphosphite were added and the polymerization was continued for $24 \mathrm{~h}$. The cloudy reaction mixture was diluted with 3 $\mathrm{mL}$ of NMP and precipitated into $150 \mathrm{~mL}$ of methanol; the colorless solid was filtered and washed with methanol and dried under vacuum for several days $(0.36 \mathrm{~g})$. The polymer $(200 \mathrm{mg}$ ) was dissolved in $5 \mathrm{~mL}$ of NMP and precipitated into $200 \mathrm{~mL}$ of methanol and dried at room temperature under vacuum for several days.

FLUODA/ISOPA/"60C20" rotaxane polymer HL137: ISOPA (0.166 g, $1.00 \mathrm{mmol})$, $0.348 \mathrm{~g}(1.00 \mathrm{mmol})$ of FLUODA, $0.56 \mathrm{~mL}(6.8 \mathrm{mmol})$ of pyridine, $2.0 \mathrm{ml}$ of NMP, 0.880 $\mathrm{g}(1.00 \mathrm{mmol})$ of "60C20", and $0.146 \mathrm{~g}(3.48 \mathrm{mmol})$ of $\mathrm{LiCl}$ were mixed under nitrogen and heated at $100{ }^{\circ} \mathrm{C}$. To this, $0.53 \mathrm{~mL}(2.0 \mathrm{mmol})$ of triphenylphosphite were added, producing a somewhat cloudy mixture. The polymerization was continued overnight. The cloudy mixture was treated with $2.0 \mathrm{~mL}$ of NMP to dissolve everything and this solution was precipitated into $200 \mathrm{~mL}$ of methanol; the colorless polymer was filtered and washed with methanol $(0.60 \mathrm{~g})$. A portion of the polymer was dissolved in the minimum volume of NMP and precipitated into $>10 \mathrm{X}$ that volume of methanol. Another portion of the polymer was dissolved in the minimum volume of DMSO and precipitated into $>10 \mathrm{X}$ that volume of methanol. The colorless polymer was dried at room temperature under vacuum for several days after each precipitation. ${ }^{1} \mathrm{H}$ NMR (DMSO$\left.d_{6}\right): 10.39(\mathrm{~s}, 2 \mathrm{H}), 8.43(\mathrm{~s}, 1 \mathrm{H}), 8.07(\mathrm{~d}, J=8 \mathrm{~Hz}, 2 \mathrm{H}), 7.91(\mathrm{~d}, \mathrm{~J}=7 \mathrm{~Hz}, 2 \mathrm{H}), 7.65$ (d, J $=9 \mathrm{~Hz}, 4 \mathrm{H}), 7.46(\mathrm{t}, \mathrm{J}=8 \mathrm{~Hz}, 1 \mathrm{H}), 7.2-7.4(\mathrm{~m}, 6 \mathrm{H}), 7.10(\mathrm{~d}, \mathrm{~J}=9 \mathrm{~Hz}, 4 \mathrm{H}), 3.50(\mathrm{~s}$, “60C20”).

ODA/ISOPA/"60C20" rotaxane polymer HL139: ISOPA (0.166 g, $1.00 \mathrm{mmol}), 0.200 \mathrm{~g}$ $(1.00 \mathrm{mmol})$ of ODA, $0.56 \mathrm{~mL}(6.8 \mathrm{mmol})$ of pyridine, $2 \mathrm{ml}$ of NMP, $0.880 \mathrm{~g}(1.00 \mathrm{mmol})$ 
of "60C20", and $0.146 \mathrm{~g}(3.48 \mathrm{mmol})$ of $\mathrm{LiCl}$ were mixed under nitrogen and heated at $100{ }^{\circ} \mathrm{C}$. To this, $0.53 \mathrm{~mL}(2.0 \mathrm{mmol})$ of triphenylphosphite were added, producing a somewhat cloudy mixture. The polymerization was continued overnight. The cloudy mixture was treated with $2 \mathrm{~mL}$ of NMP to dissolve everything and this solution was precipitated into $200 \mathrm{~mL}$ of methanol; the colorless polymer was filtered and washed with methanol. A portion of the polymer was dissolved in the minimum volume of NMP and precipitated into $>10 \mathrm{X}$ that volume of methanol. Another portion of the polymer was dissolved in the minimum volume of DMSO and precipitated into $>10 \mathrm{X}$ that volume of methanol. The colorless polymer was dried at room temperature under vacuum for several days after each precipitation. ${ }^{1} \mathrm{H}$ NMR $\left(\mathrm{DMSO}_{-} d_{6}\right): 10.44(\mathrm{~s}, 2 \mathrm{H}), 8.51(\mathrm{~s}, 1 \mathrm{H})$, $8.13(\mathrm{~d}, J=8 \mathrm{~Hz}, 2 \mathrm{H}), 7.79(\mathrm{~d}, J=9 \mathrm{~Hz}, 2 \mathrm{H}), 7.67(\mathrm{t}, J=8 \mathrm{~Hz}, 1 \mathrm{H}), 7.03(\mathrm{~d}, J=9 \mathrm{~Hz}$ 2H), 3.50 (s, “60C20").

Nylon 6,6: HMD (0.8922 g, $7.677 \mathrm{mmol})$ and $40.0 \mathrm{~mL}$ of dry diglyme were mixed under nitrogen. HMD did not dissolve, so the mixture was heated in an oil bath at $100{ }^{\circ} \mathrm{C}$; HMD dissolved. To this $2.14 \mathrm{~mL}(7.68 \mathrm{mmol})$ of triethylamine were added using a syringe and then a preweighed vial containing $1.4053 \mathrm{~g}(7.677 \mathrm{mmol})$ of adipoyl chloride was carefully dropped into the reaction mixture. The polymerization was very fast and the mixture gelled instantly. Heating was continued for 14 hours at the same temperature. The polymerization mixture was cooled, filtered and the solid was washed with acetone, water, THF and acetone and dried at room temperature under vacuum, $1.73 \mathrm{~g} \mathrm{(77 \% ).}{ }^{1} \mathrm{H}$ NMR (270 MHz, $\left.\mathrm{CF}_{3} \mathrm{COOD}\right): 3.5$ (br s, 4H), 2.79 (br s, 4H), 1.94 (br s, 4H), $1.76(\mathrm{br} \mathrm{s}, 4 \mathrm{H}), 1.49$ (br s, 4H).

Polyrotaxane of Nylon 6,6 and 30-Crown-10: HMD (1.0680 g, $9.190 \mathrm{mmol})$ and 5.18 g (11.7 mmol, 1.28 eq.) of $30 \mathrm{C} 10$ were melted in a dry polymerization kettle under 
nitrogen and stirred for an hour at $50-60^{\circ} \mathrm{C}$ (using a water bath). The color turned from light cream to yellowish green within $10 \mathrm{~min}$. To this $10 \mathrm{~mL}$ of chloroform and triethylamine $(2.8 \mathrm{~mL}, 20 \mathrm{mmol})$ were added, followed by addition of $1.6821 \mathrm{~g}(9.190$ $\mathrm{mmol}$ ) of adipoyl chloride in chloroform in less than $10 \mathrm{sec}$. The polymerization began immediately, giving an insoluble solid. The reaction was very exothermic and it caused the chloroform to evaporate rapidly under the nitrogen stream. Thus, $10 \mathrm{~mL}$ of dry DMF were added to the insoluble solid and the reaction mixture was stirred for $3.5 \mathrm{~h}$ at room temperature. The reaction mixture was poured into $400 \mathrm{~mL}$ of water, stirred for an hour and filtered and washed with water $(5 \times 50 \mathrm{ml})$ and dried, $1.45 \mathrm{~g}(70 \%)$. The dry polymer $(1.0 \mathrm{~g})$ was suspended in methanol and stirred for 1.5 hours, filtered and washed with methanol $(5 \times 50 \mathrm{ml})$ and dried at room temperature under vacuum $(0.70 \mathrm{~g}) .{ }^{1} \mathrm{H}$ NMR (270 MHz, $\left.\mathrm{CF}_{3} \mathrm{COOD}\right): 3.96$ (br s, $\left.0.98 \mathrm{H}, 30 \mathrm{C} 10\right), 3.5$ (br s, 4H), 2.79 (br s, 4H), 1.94 (br s, 4H), 1.76 (br s, 4H), 1.49 (br s, 4H).

\section{REFERENCES}

1. a) Gibson, H. W. in Large Ring Molecules, J. A. Semlyen, ed., J. Wiley and Sons, New York, 1996, ch. 6, pp. 191-262; b) Mahan, E.; Gibson, H. W. in Cyclic Polymers, 2nd ed., Semlyen, A. J., ed., Kluwer Publishers, Dordrecht, 2000, ch. 12, pp. 415-560; c) Evans, N. H.; Beer, P. D. Chem. Soc. Rev. 2014, 43, 46584683; d) Bruns, C. J.; Stoddart, J. F. Acc. Chem. Res. 2014, 47, 2186-2199; e) Xue, M.; Yang, Y.; Chi, X.; Yan, X.; Huang, F. Chem. Rev. 2015, 115, 73987501.

2. a) Gibson, H. W.; Marand, H. Adv. Materials 1993, 5, 11-21. b) Gibson, H. W.; Bheda, M. C.; Engen, P. T. Prog. Polym. Sci., 1994, 19, 843-945; c) Huang, F.; Gibson, H. W. Progr. Polym. Sci. 2005, 30, 982-1018; d) Niu, Z.; Gibson, H. W. 
Chem. Rev. 2009, 109, 6024-6046; e) Fang, L.; Olson, M. A.; Benitez, D.; Tkatchouk, E.; Goddard, W. A., III; Stoddart, J. F. Chem. Soc. Rev. 2010, 39, 1729; f) Murugan, A.; Gibson, H. W. Progr. Polym. Sci., 2014, 39, 1043-1073; g) Harada, A.; Hashidzume, A.; Yamaguchi, H.; Takashima, Y. Encyclopedia of Polymer Science and Technology (4th ed.) 2014, 11, 119-149.

3. a) Gibson, H. W.; Liu, S.; Lecavalier, P.; Wu, C.; Shen, Y. X. J. Am. Chem. Soc. 1995, 117, 852-874; b) Gibson, H. W.; Liu, S. Makromol. Chem., Macromol. Symp. 1996, 102, 55-61; c) Gong, C.; Gibson, H. W. Macromolecules 1996, 29, 7029-7033; d) Gibson, H. W.; Liu, S.; Gong, C.; Joseph, E. Macromolecules 1997, 30, 3711-3727; e) Gong, C; Gibson, H. W. Macromol. Chem. Phys. 1997, 198, 2331-2342; f) Gong, C.; Ji, Q.; Glass, T. E.; Gibson, H. W. Macromolecules 1997, 30, 4807-4813; g) Gibson, H. W.; Nagvekar, D.; Powell, J.; Gong, C.; Bryant, W. Tetrahedron 1997, 53, 15197-15207; h) Gong, C.; Gibson, H. W. Angew. Chem. Int. Ed. Engl. 1998, 37, 310-314; i) Gong, C.; Balanda, P. B.; Gibson, H. W. Macromolecules 1998, 31, 5278-5289.

4. a) Shen, Y. X.; Gibson, H. W. Macromolecules 1992, 25, 2058-2059; b) Shen, Y. X.; Xie, D.; Gibson, H. W. J. Am. Chem. Soc. 1994, 116, 537-548; b) Marand, E.; Hu, Q.; Gibson, H. W.; Veytsman, B. Macromolecules 1996, 29, 2555-2562 d) Gong, C.; Gibson, H. W. Angew. Chem. Int. Ed. Engl. 1997, 36, 2331-2333; e) Gong, C.; Gibson, H. W. J. Am. Chem. Soc. 1997, 119, 8585-8591; f) Gong, C.; Gibson, H. W. Macromolecules 1997, 30, 8524-8525; g) Gong, C.; Subramanian, C.; Ji, Q.; Gibson, H. W. Macromolecules 1998, 31, 1814-1818.

5. a) Delaviz, Y.; Gibson, H. W. Macromolecules 1992, 25, 4859-4862; b) Gibson, H. 
W.; Nagvekar, D. S.; Yamaguchi, N.; Bhattarcharjee, S.; Wang, H.; Vergne, M.; Hercules, D. M. Macromolecules 2004, 37, 7514-7529.

6. Lee, S.-H.; Engen, P. T.; Gibson, H. W. Macromolecules 1997, 30, 337-343; b) Gibson, H. W.; Engen, P. T.; Lee, S.-H. Polymer 1999, 40, 1823-1832.

7. Gong, C.; Gibson, H. W. J. Am. Chem. Soc. 1997, 119, 5862-5866; b) Yamaguchi, N.; Gibson, H. W. Macromol. Chem. Phys. 2000, 201, 815-824; c) Gibson, H. W.; Bryant, W. S.; Lee, S.-H. J. Polym. Sci., Polym. Chem. Ed. 2001, 39, 1978-1993.

8. Negi, Y. S.; Razdan, U.; Saran, V. J. Macromol. Sci., Part C: Polym. Rev. 1999, 39, 391-403J; b) Page, L. B. RAPRA Rev. Rep. 2000, 11, 3-145; c) Kotek, R.; Jung, D.; Tonelli, A. E.; Vasanthan, N. J. Macromol. Sci., Polym. Rev. 2005, C45, 201-230; d) Cui, X.; Yan, D. Leading Edge Polym. Res. 2006, 65118; e) Gallini, J.; Kirk-Othmer Encyclopedia of Chemical Technology (5th ed.), Seidel, A., ed., 2006, 19, 713-738; f) García, J. M.; García, F. C.; Serna, F.; de la Peña, J. L. Progr. Polym. Sci. 2010, 35, 623-686; g) Buckwalter, J. M.; Dennis, J.; Long, T. E. Progr. Polym. Sci. 2015, 45, 1-22; h) Cortez-Lemus, N. A.; Licea-Claverie, A. Progr. Polym. Sci. 2015, in Press, Available online 14 August.

9. Yamazaki, N.; Higashi F.; Kawabata, J. J. Polym. Sci., Polym. Chem. Ed. 1974, 12, 185-191; b) Yamazaki, N.; Higashi F.; Kawabata, J. J. Polym. Sci., Polym. Chem. Ed. 1974, 12, 2149-2154; c) Yamazaki, N.; Matsumoto M.; Higashi F.; J. Polym. Sci., Polym. Chem. Ed. 1975, 13, 1373-1380; d) Higashi F.; Nakano, Y.; Goto, M.; Kakinoki, H. J. Polym. Sci., Polym. Chem. Ed. 1980, 18, 1099-1104; e) Higashi F.; Taguchi, Y.; Kokubo, N.; Ohta, H. J. Polym. Sci., Polym. Chem. Ed. 
1981, 19, 2745-2750; f) Higashi F.; Taguchi, Y. J. Polym. Sci., Polym. Chem. Ed. 1981, 19, 3345-3349; g) Higashi F.; Ogata, S.-I.; Aoki, Y. J. Polym. Sci., Polym. Chem. Ed. 1982, 20, 2081-2087; h) Higashi F.; Akiyama, N.; Ogata, S.-I. J. Polym. Sci., Polym. Chem. Ed. 1983, 21, 913-916; i) Higashi F.; Mochizuki, A. J. Polym. Sci., Polym. Chem. Ed. 1983, 21, 3337-3340; j) Yamazaki, N.; Higashi, F. Adv. Polym. Sci. 1981, 38, 1-25; k) Imai, Y.; Kajiyama, M.; Ogata S.-I.; Kakimoto, M. J. Polym. Sci., Polym. Chem. Ed. 1984, 22, 3183-3188.

10. a) Gibson, H. W.; Bheda, M. C.; Engen, P.; Shen, Y. X.; Sze, J.; Zhang, H.; Gibson, M. D.; Delaviz, Y.; Lee, S. H.; Wang, L.; Rancourt, J.; Taylor, L. T. J. Org. Chem. 1994, 59, 2186-2196; b) Gibson, H. W.; Liu, S.; Lecavalier, P.; Wu, C.; Shen, Y. X. J. Am. Chem. Soc. 1995, 117, 852-874.

11. Prof. Colin Booth and his colleagues at the University of Manchester, U.K., discovered by GPC using a well calibrated multiple column instrument that the crown ether targeted for a ring size of 60 atoms is not a pure, single-sized macrocycle. Rather, it is a mixture of cyclics ranging upwards from the target size to cyclics with perhaps 80 repeat units, i. e., $240 \mathrm{C} 80$, and perhaps catenanes. [For a catenane derived from a similar system, " 42 -crown-14", and constituting $\sim 8 \%$ of the total mixture, see Gibson, H. W.; Lee, S.-H. Can. J. Chem. 2000, 78, 347-355.] By NMR spectroscopy there are no detectable amounts of the linear tosylate or glycol starting materials, nor vinyl ether moieties in the samples (see ESI, Figures S1 and S2); elemental analysis confirmed its composition. ${ }^{10 a}$ Electrospray ionization mass spectrometric evidence is provided for the presence of $[30 \mathrm{C} 10]_{n}, n$ $=2$ to 7 (ESI, Figure S3). However, $30 \mathrm{C} 10$ is a pure compound. ${ }^{12}$ In this paper we will use quotation marks around the "60C20" name to designate the size of the 
crown ether that was the target of the synthesis. For a discussion of "42C14" and related systems see: Booth, C.; Price, C. in Cyclic Polymers ( $2^{\text {nd }}$ ed. $)$, J. A.Semlyn, ed., Kluwer, Dordrecht, pp. 229-270.

12. Bheda, M.; Merola, J.; Woodward, W.; Vasudevan, V.; Gibson, H. W. J. Org. Chem. 1994, 59, 1694-1702.

13. Dai, Z.; Li, Y.; Yang, S.; Zhao, N.; Zhang, X.; Xu, J. Eur. Polym. J. 2009, 45, 1941 1948. b) Shibasaki, Y.; Koizumi, T.; Nishimura, N.; Oishi, Y. Chem. Lett. 2011, 40, 1132-1134.

14. Without the crown ether the reaction mixture was homogenous.

15. Williams, D. H. Aldrichimica 1991, 24, 71-80.

16. Jaffe, M.; Jones, R. S. Handbook of Fiber Science and Technology, Vol III, High Technology Fibers, Part A; Lewin M.; Preston, J., eds., Marcel Dekker Inc., New York (1985).

17. Zimmerman, J. Encyclopedia of Polymer Science and Engineering, 2nd ed., John Wiley \& Sons, New York, NY, (1987), Vol. 11, p. 315.

18. Nagapudi,K.; Hunt, J.; Shepherd, C.; Baker, J.; Beckham, H. W. Macromol. Chem. Phys. 1999, 200, 2341-2349.

19. a Mendolia, M. S.; Farrington, G. C. Adv. Chem. 1995, 245, 107-130; b) Bruce, P. G. Dalton Trans. 2006, 1365-1369; c) Shamsipur, M.; Alizadeh, N.; Rofouei, M. K.; Alizadeh, K. Polish J. Chem. 2007, 81, 1743-1752; d) Inokuchi, Y.; Boyarkin, O. V.; Kusaka, R.; Haino, T.; Ebata, T.; Rizzo, T. R. J. Am. Chem. Soc. 2011, 133, 12256-12263. 
20. Handbook of Chemistry and Physics, $52^{\text {nd }}$ ed., 1971-2, p. C328.

21. Merck Index, $12^{\text {th }}$ ed., 1996 , p. 802.

22. Handbook of Chemistry and Physics, $52^{\text {nd }}$ ed., 1971-2, p. C329. 

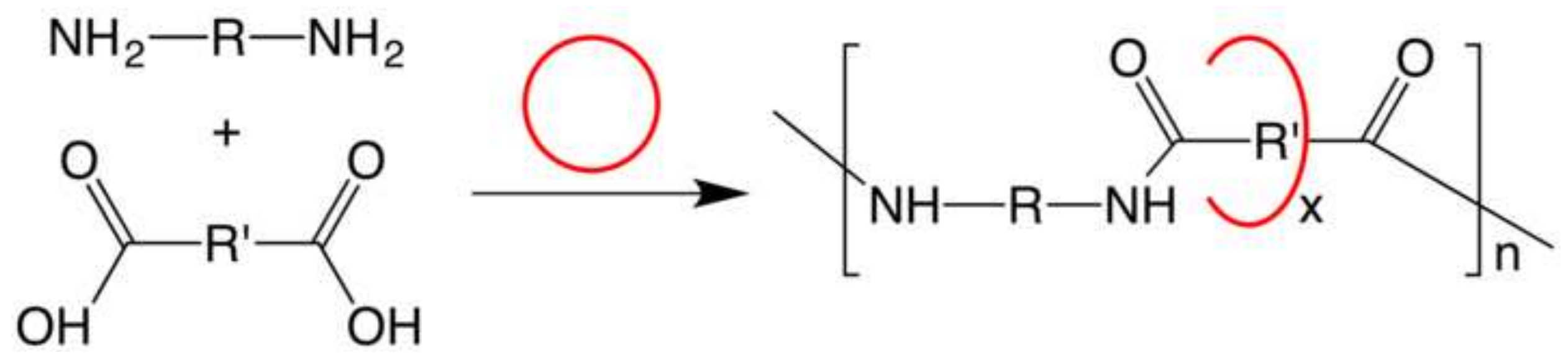